\title{
Residential solar PV policy: An analysis of impacts, successes and failures in the Australian case
}

\section{$\operatorname{AUTHOR}(S):$}

Chapman, Andrew J.; McLellan, Benjamin; Tezuka, Tetsuo

\section{CITATION:}

Chapman, Andrew J....[et al]. Residential solar PV policy: An analysis of impacts, successes and failures in the Australian case. Renewable Energy 2016, 86: 1265-1279

\section{ISSUE DATE: \\ 2016-02 \\ URL: \\ http://hdl.handle.net/2433/241778 \\ RIGHT:}

(c) 2016 This manuscript version is made available under the CC-BY-NC-ND 4.0 license

http://creativecommons.org/licenses/by-nc-nd/4.0/; The full-text file will be made open to the public on 1 February

2018 in accordance with publisher's 'Terms and Conditions for Self-Archiving'; この論文は出版社版でありません。引用 の際には出版社版をご確認ご利用ください。; This is not the published version. Please cite only the published version. 
Please reference the final published version, available at:

https://doi.org/10.1016/j.renene.2015.09.061

\section{Residential Solar PV Policy: An analysis of impacts, successes and failures in the Australian case}

Andrew J. Chapman ${ }^{1}$, Benjamin McLellan, Tetsuo Tezuka

Graduate School of Energy Science, Kyoto University, Yoshida Honmachi, Sakyo-ku, Kyoto 6068501, Japan.

\section{Abstract}

Residential or 'rooftop' solar PV can play an important role in providing renewable energy, thus offsetting fossil fuel based generation and associated greenhouse gas emissions. In Australia, subsidies are offered to encourage the deployment of residential PV in the form of Renewable Energy Certificates (RECs) and Feed-in Tariffs (FiTs). This paper provides a literature review of existing work which assesses renewable energy in Australia, and delves deeper into a residential PV specific analysis of available data across the five criteria of installation, employment, market maturity, FiT settings and environmental outcomes to assess successes, failures and impacts of Australian residential PV policies between 2001 and 2012. This analysis identifies overall success with regard to environmental and deployment goals, and limited success in the goal of renewable energy industry promotion, which is devoid of indigenous manufacturing. In addition, impacts, including the dominance of the FiT as the initial stimulus for rapid PV deployment, cost impacts on electricity bills for various FiT settings, and the dependence of PV employment numbers on the continuation of the FiT are also identified. Finally, inequitable outcomes due to the FiT, such as crosssubsidisation from non-solar to solar households are also detailed.

Keywords: photovoltaics; feed-in-tariff; policy; renewable energy; employment; equity.

\section{Introduction}

Governments around the world are attempting to stimulate the installation of renewable energy at the community level as part of an overall strategy to achieve energy security (Cherrington et al, 2013) and address climate change by reducing greenhouse gas (GHG) emissions (Buckman and Diesendorf, 2010). In order to achieve desired installation targets, governments use a variety of stimulatory policies and tools including Feed-in Tariffs (FiT), point of sale rebates, including Renewable Energy Certificates (REC), and tax benefits. These policies have been successful in increasing installations around the world, most

\footnotetext{
${ }^{1}$ Corresponding author. Email: chapman.john.27e@st.kyoto-u.ac.jp Phone: +81 757533300
} 
Please reference the final published version, available at:

https://doi.org/10.1016/j.renene.2015.09.061

prominently for solar photovoltaic (PV) systems within the residential sector (e.g. Japan (Muhammad-Sukki et al, 2014) and the United Kingdom (Cherrington et al, 2013)). In this study, the Australian case is analysed as a useful example with good data availability, in a country that has a very high GHG emissions intensity in its electricity generation mix and good theoretical potential for solar energy.

This study brings together analysis of five criteria which are impacted directly by State and Federal PV policy settings; installation rates and impetus for installation, employment, market development, gross and net FiT analysis and environmental outcomes. Whilst other papers have assessed single factors or policies at a high level, this paper provides detailed analysis of the impacts within each of the five criteria and provides a definitive determination of the successes, failures and impacts of residential PV policies in Australia, when measured against stated government targets.

Whilst FiT and REC settings have fluctuated over time, key goals of Australian renewable energy policy have been met, including the installation of significant amounts of new renewable energy sources, in this case residential PV. In addition, this installation of PV has ensured that a small proportion of the environmental target of greenhouse gas reduction as part of Australia's Kyoto Protocol commitments has been met, and some fossil fuel based electricity generation will be subsequently displaced within the Australian electricity market. The achievement of these goals is noteworthy, however it is also apparent from this study that the rapidly changing, unstable nature of policy settings has not boded well for industry development, indeed Australian PV-related employment levels are significantly lower than in Europe and America, and growth is not being sustained due to ever-decreasing, and in some cases disappearing FiT regimes.

The paper is presented in four parts: Section 1 outlines the background of Australian residential PV policies and provides a literature review of existing scholarly analysis of these policies. Section 2 details the impacts of these policies between 2001 and 2012 across the criteria of installation, employment, market maturity effects, FiT settings and environmental outcomes, based on data collected from a wide variety of Australian and international sources. Section 3 provides analysis of these outcomes, detailing successes, failures and future ramifications across these five criteria. Section 4 summarises these findings and outlines future work.

\subsection{Background}

The three broad goals of the Australian Renewable Energy Target (RET) are; 
Please reference the final published version, available at:

https://doi.org/10.1016/j.renene.2015.09.061

1. To encourage additional renewable-based electricity generation, ensuring that renewable energy sources are ecologically sustainable;

2. To reduce GHG emissions in the electricity sector; and

3. To promote renewable energy industry development (Clean Energy Regulator, 2012).

The first renewable energy target established in Australia was the Mandatory Renewable Energy Target (MRET) which began in April 2001. The MRET was a federal target to be achieved by the subordinate State governments through additional generation of electricity from ecologically sustainable renewable sources and a reduction in greenhouse gas emissions (Renewable Energy (Electricity) Act 2001, s3). The MRET created a new entity, known as the Office of the Renewable Energy Regulator, responsible for accrediting renewable energy generators and allocating Renewable Energy Certificates (RECs) (equivalent to one megawatt hour of renewable energy anticipated to be generated under specified modelling conditions) to each generator. These RECs are allocated for the life of the technology and can be claimed as a cash incentive (usually at point of purchase) in addition to financial benefits gained from generating or displacing electricity. These RECs are then purchased by electricity retailers and large electricity customers to meet their 'mandatory' renewable energy acquisition targets (Kent and Mercer, 2006).

From 1 January 2011 the MRET was renamed the Renewable Energy Target (RET) operating in two parts; the Large-scale Renewable Energy Target (LRET) and the Smallscale Renewable Energy Scheme (SRES). These two parts are operated individually to ensure that the LRET encourages the deployment of large scale renewables such as wind farms, whilst the SRES aims to increase the deployment of small scale renewable technologies such as solar photovoltaic (PV) panels and solar hot water heaters (Department of Industry, Innovation, Climate Change, Science, Research and Tertiary Education, 2011).

The RET aims to deliver at least twenty per cent of Australia's electricity from renewable sources by 2020, with 41 TWh sourced from large scale renewable energy sources, and to provide long term support for renewable energy industries through to 2030 . The mechanisms in use to achieve these goals are modified RECs, called Large Generation Certificates for large-scale renewable energy generation and Small-scale Technology Certificates (STC) for small-scale renewable energy generation. STC's are issued for solar panel systems at the time of installation for 15 years of expected system output (Department of Industry, Innovation, Climate Change, Science, Research and Tertiary Education, 2011). 
Please reference the final published version, available at:

https://doi.org/10.1016/j.renene.2015.09.061

Prior to 2013, an additional financial benefit was available to installers of solar panels in the form of solar credits. Solar credits applied to the first 1.5 kilowatts $(\mathrm{kW})$ of capacity installed and multiply the amount of STC's which can be issued. From 9 June 2009 to 30 June 2011, STC's were multiplied by five, from 1 July 2011 to 30 June 2012, STC's were multiplied by 3 , and from 1 July 2012 to 31 December 2012, STC's were multiplied by 2. On 1 January 2013, the multiplier was removed, 6 months ahead of schedule (Clean Energy Regulator, 2012). Figure 1 outlines the schemes applicable to residential PV, and REC multipliers offered in Australia between 2001 and 2012. These multipliers were applicable at the time of purchase in the form of an additional point of sale rebate, during the stated periods.

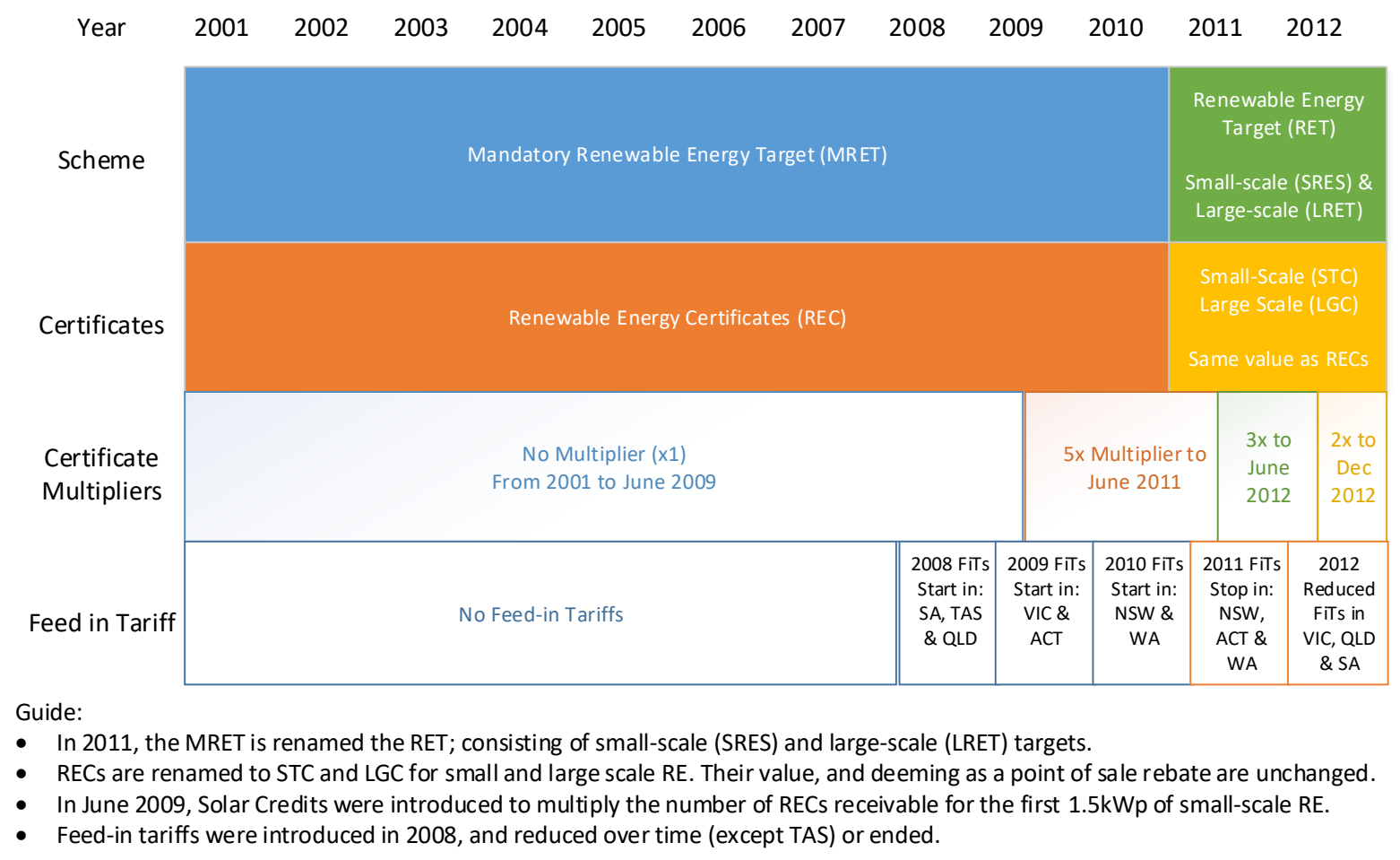

Figure 1. Renewable energy schemes and REC multipliers 2001-2012

In addition to the federally operated REC and Solar Credit Schemes, FiTs in Australia were introduced in 2008, administered by State governments as an additional incentive for householders to install rooftop PV. The FiTs varied in each state and were either offered as a gross FiT, where all electricity generated in the household is purchased at a set tariff, or as a net FiT, where only the electricity which is generated in excess of household consumption is purchased. The net FiT was the most popular, and sought not only to reward installers for the value of their exported solar electricity but also to encourage people to use electricity in the household outside of generation times in order to yield the greatest benefit from tariff payments. FiTs began at a generous 44 cents per kilowatt hour (net) in South Australia on 1 
Please reference the final published version, available at:

https://doi.org/10.1016/j.renene.2015.09.061

July (DMITRE, 2013) and in Queensland 1 June (QCA, 2013), and a payment equivalent to the price of electricity in Tasmania through a single energy supplier (Aurora Energy, 2014). On 1 January 2009 Victoria introduced their FiT at 60 cents (DSDBI, 2014), and the Australian Capital Territory introduced the first gross FiT at 50.5 cents (ESDD, 2013). The last two States to introduce an FiT were New South Wales at 60 cents gross on 1 January, 2010 (NSW Trade and Investment, 2013) followed by Western Australia on 1 July at 40 cents net (WA Department of Finance, 2013). No centrally administered Territory-wide FiT was established in the Northern Territory (Access Economics, 2008). Table 1 outlines the introduction timeline and changing levels of FiT across Australia. The FiTs shown are specific to the timing of solar installation, and vary in contract period. For example A system installed in Queensland in 2008 is eligible for the 44 cent FiT until 2028, whereas one installed after 10 July 2012 is only eligible for the 8 cent FiT.

Table 1. Feed-in Tariffs in Australia 2008-2012

\begin{tabular}{|c|c|c|c|c|c|}
\hline State & 2008 & 2009 & 2010 & 2011 & 2012 \\
\hline SA & $44 c$ & $44 c$ & $44 c$ & $44 c \Rightarrow 16 c(1 \mathrm{Oct})$ & $16 \mathrm{c}$ \\
\hline WA & No FiT & No FiT & $40 c$ & $\begin{array}{c}40 c \Rightarrow 20 c(1 \mathrm{Jul}) \Rightarrow \\
\text { Closed (1 Aug) }\end{array}$ & No Fit \\
\hline TAS & 1 for 1 & 1 for 1 & 1 for 1 & 1 for 1 & 1 for 1 \\
\hline VIC & No Fit & $60 c$ & $60 c$ & $60 c$ & $25 c$ \\
\hline NSW & No Fit & No Fit & $\begin{array}{c}60 c \text { Gross } \Rightarrow 20 c \text { Net } \\
(27 \text { Oct) }\end{array}$ & $\begin{array}{c}20 c \Rightarrow \text { Closed } \\
\text { (28 April) }\end{array}$ & No Fit \\
\hline ACT & No Fit & $50.5 c$ & $\begin{array}{c}\text { 50.5c Gross } \Rightarrow 45.7 \mathrm{c} \\
(1 \mathrm{Jul})\end{array}$ & $\begin{array}{c}\text { 45.7c } \Rightarrow \text { Closed } \\
\text { (30 May) }\end{array}$ & No Fit \\
\hline QLD & $44 \mathrm{c}$ & $44 c$ & $44 c$ & $44 c$ & $44 c \Rightarrow 8 c(10 \mathrm{Jul})$ \\
\hline
\end{tabular}

(Notes: $\Rightarrow$ shows a change in tariff, 1 for 1 means that the tariff is equal to the price of electricity)

Australia has one of the highest average solar irradiation levels of any continent in the world, approximately 58 million petajoules (PJ) per annum, equivalent to 16 trillion megawatt hours (MWh) per annum (Byrnes et al, 2013), and can therefore realise the greatest benefit from the deployment of solar technologies. Australian households have proven to be very responsive to financial incentives for the deployment of PV (Access Economics, 2008) including RECs and FiTs as administered by State and Territory Governments as explained in Section 2.

\subsection{Previous Analysis}

Other studies have critiqued the RET; in particular its overall success in achieving in excess of the targeted $9500 \mathrm{GWh}$ of new renewable energy by 2010 , achieved predominantly by large scale wind. This trend is likely to continue; under the RET, it is likely that Australia will be able to source a quarter of its electricity needs from renewable sources, mainly from wind and existing hydro-electricity resources by 2020 (Elliston et al, 2014). Whilst this current, and 
Please reference the final published version, available at:

https://doi.org/10.1016/j.renene.2015.09.061

potential future achievement of significant renewable energy electricity supply has positive environmental ramifications, it has been identified as having an unequal impact on wholesale and retail electricity prices, with energy intensive industries who are partially exempt from RET costs enjoying lower electricity prices at the expense of households who generally pay a RET pass-through cost (i.e. 'green' surcharges on electricity bills) without a price reduction benefit (Cludius et al, 2014).

Australia is identified as a prime candidate for support to expand renewable energy sources to reduce reliance on a predominantly coal-fired, relatively cheap electricity supply (Moosavian et al, 2013; Zahedi, 2010); which is one of the key causes of Australia being the highest per capita GHG emitter in the developed world (Bahadori et al, 2013). In fact, due to Australia's reliance on coal-fired power, the electricity generated within the National Electricity Market (NEM) is responsible for approximately one third of all national emissions (Garnaut, 2011). In spite of this need, and the opportunity to reduce GHG emissions via renewable energy deployment, PV has proven to be a high generation cost energy source (Effendi and Courvisanos, 2012), which requires generous support mechanisms to be competitive with fossil fuel generation sources (Buckman and Diesendorf, 2010). In addition, small scale PV is partially subsidised by state FiTs which are funded by all electricity customers within the local network. This has been shown to cause cross-subsidisation from non-solar households to solar households in the form of increased electricity bills. Further, as home ownership is a key criteria for the installation of solar panels, electricity customers who do not own their own home cannot take advantage of either the REC or FiT subsidies (Nelson et al, 2011).

Macintosh and Wilkinson (2011) assessed the public benefits of solar subsidies to 2010, and found that although government intervention did rapidly increase deployment off an almost zero base, the overall environmental impact was low, with an insignificant contribution from PV to grid based electricity, with a very high cost of $\mathrm{CO}_{2}$ abatement. Further, the mechanism implemented, the REC, in combination with Solar Credit multipliers and the attribution of RECs to non-generating technologies (Solar hot water systems) caused a phantom supply (i.e. a significant number of RECs above and beyond the actual renewable energy generating capacity installed), which lead to a subsequent depression in the value of each $\mathrm{REC}$, which may have reduced investment in small scale renewable energy. Further, Simpson and Clifton (2014) suggest that this excess generation of RECs lead to retailers purchasing sufficient certificates to cover their RET liability for many years, further depressing the price of RECs, effectively stalling large scale investment for many years into the future as well. Valentine (2010) also investigated the phantom REC generation issue 
Please reference the final published version, available at:

https://doi.org/10.1016/j.renene.2015.09.061

supporting small scale renewable technologies, and also criticises the RET as being too short, ill-structured and having insufficient generation targets out to 2020 (and no clear post 2020 support path) suggesting this regime is unlikely to stimulate large scale, long term investment.

The crowding of the REC market by small scale generators was somewhat rectified by the separation of the RET into the SRES and LRET, with separate generation targets and certificate types, however, stockpiles of RECs held by liable parties are estimated to stall investment in large scale generation out to 2015/16. Further, it is clear that each REC multiplier reduction caused large spikes in sales, leading to a decreased value of RECs, and a reduction in quality of system installations due to time constraints at the end of each multiplier period. Also, following each spike installers experienced uncertainty due to low installation rates and in some cases insolvency (Simpson and Clifton, 2014; Buckman and Diesendorf, 2010).

It became apparent that Australia's three level (local, State and Federal) governmental system caused an overly complex regulatory and policy framework for the administration of the RET. This was shown to have negative outcomes ranging from a socially sub-optimal incentive system with disparate motivations for policy development and intervention, and due to the complexity of this system difficulties arose for the integration of new technologies and participants (Byrnes et al, 2013). A pertinent example is the state of Queensland, the major installer of PV in Australia. Martin and Rice (2012) undertook stakeholder analysis to identify barriers to the development of renewable energy in Queensland, and identified that in the case of small scale generation such as PV, an inconsistent or unclear generation target and inconsistent levels of support were detrimental. Further, stakeholder analysis showed that Queensland's (and indeed Australia's) abundance of cheap coal fired power along with complex multi-tiered government approvals and lack of a skilled workforce were also barriers to developing the renewable energy supply. Additionally, an assessment of installations to the end of 2010 showed that two thirds of applicants to the program were from medium high, or high socio-economic status households (Macintosh and Wilkinson, 2011).

Whilst some of the abovementioned factors and impacts are incorporated within the detailed analysis of this study, it is unique, in that it focuses solely on residential grid-connected household PV over the period from 2001 to 2012. It identifies how this initially insignificant market has grown rapidly over a very short period due to specific, targeted government policies, and how these targeted policies have led to outcomes which have differing impacts across jurisdictions, industry sectors and the environment. 
Please reference the final published version, available at:

https://doi.org/10.1016/j.renene.2015.09.061

This paper focuses primarily on the NEM² States of Queensland, New South Wales (including the Australian Capital Territory), Victoria, South Australia and Tasmania.

\section{Outcomes of Policies}

This section uses data from Government sources, previously undertaken research, and various databases across national and international energy agencies, industry bodies, electricity suppliers and Australian PV reporting and regulatory organisations to describe the key outcomes of PV policies from 2001 to 2012 including installation rates, system sizes, employment, market growth and maturity, FiT and REC impacts and environmental outcomes. Analysis of these outcomes is undertaken in Section 3, along with a discussion of the ramifications of policy settings during this period.

\subsection{Installations and System Size}

The most immediately apparent outcome of the REC and FiT policies is the high per capita uptake of household PV. Figure 2 shows the nationwide total yearly installation rates from 2001-2012 and demonstrates the period of the Federal REC scheme, and State FiT schemes.

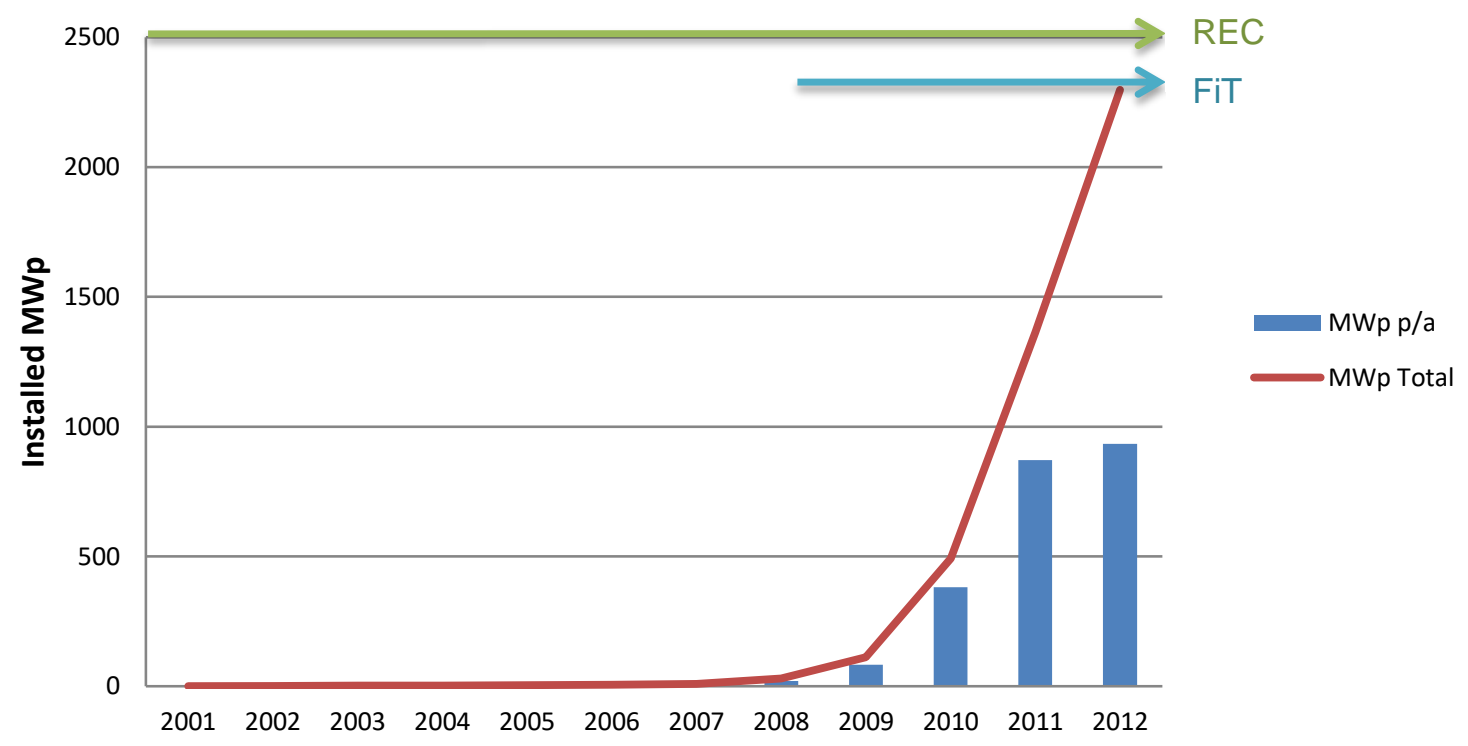

Figure 2. Cumulative and annual installed residential PV MWp (CEC, 2013)

\footnotetext{
${ }^{2}$ Western Australia and the Northern Territory (outside of the NEM) are also assessed where data is available.
} 
Please reference the final published version, available at:

https://doi.org/10.1016/j.renene.2015.09.061

At the end of 2012, Queensland had almost one-third of all PV capacity in Australia, followed by New South Wales with 22 per cent. Other states with significant levels of PV installation were Victoria, South Australia and Western Australia with 18, 15 and 12 per cent

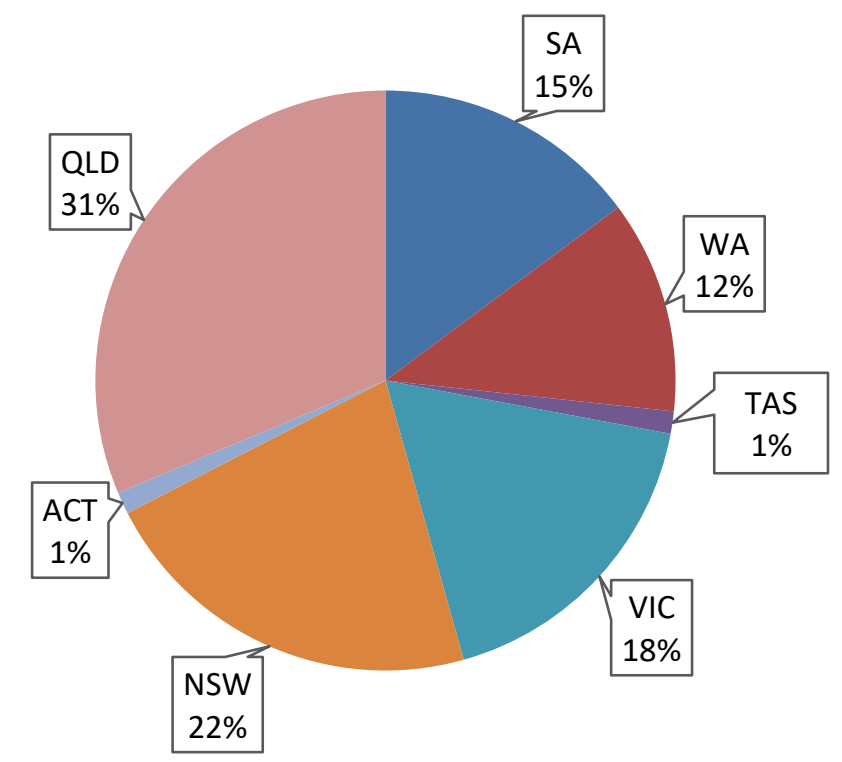

Figure 3. State share of PV installations at the end of 2012

respectively. Tasmania and the Australian Capital Territory both accounted for just one per cent, as outlined in Figure 3.

Over the same time period, the average PV system size being installed in each state also changed (Clean Energy Council, 2013) to take advantage of REC and FiT benefits as shown in Figure 4 (States with market share less than one per cent are not shown).

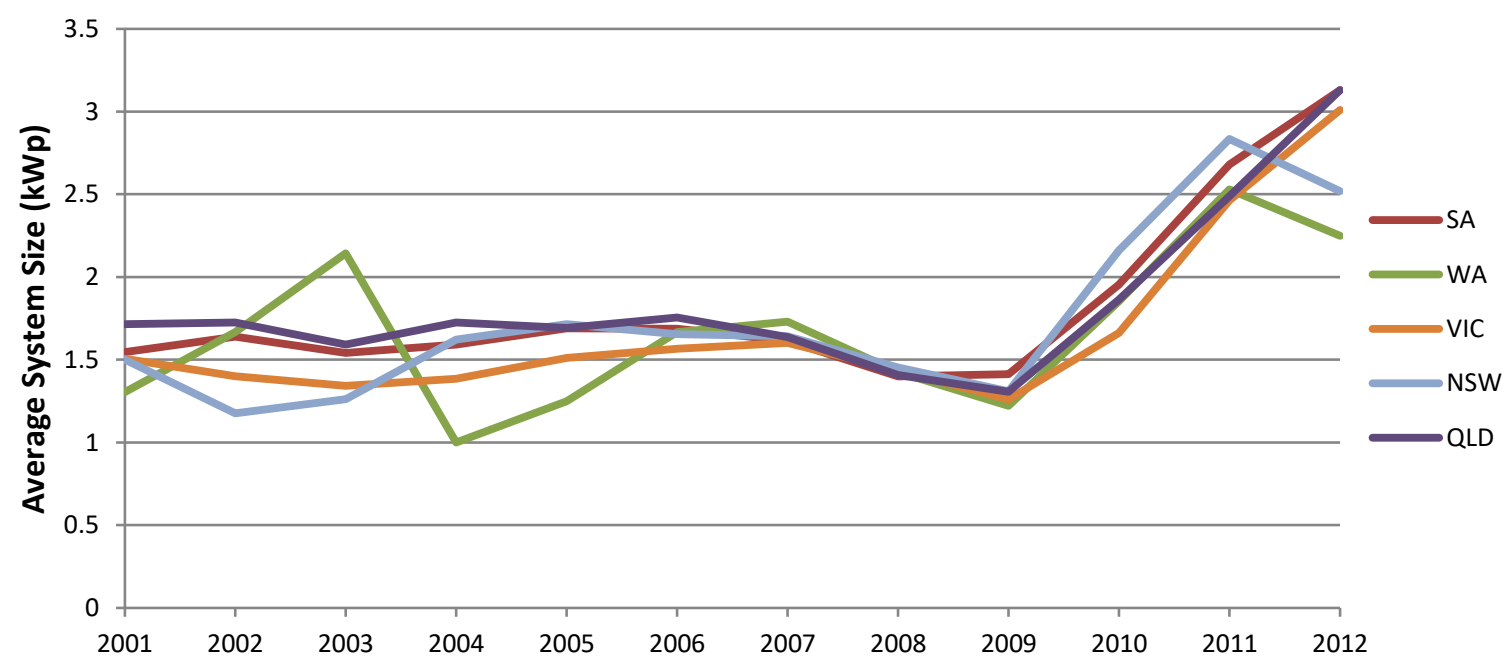

Figure 4. State average PV system size 2001-2012 
Please reference the final published version, available at:

https://doi.org/10.1016/j.renene.2015.09.061

\subsection{Employment}

Alongside installation growth in Australia, employment also boomed between 2008 and 2012 . Full time equivalent (FTE) employment numbers for PV in Australia are broken down across five groups; public research, education and training, manufacturing - including company research and development, sales, design, engineering and consulting, installation and maintenance, and electricity utility, industry support and government positions. The changing numbers of jobs is expressed in Figure $\mathbf{5}$ are adapted from data in 'PV in Australia' reports, as part of the International Energy Agency's Co-operative Program on Photovoltaic Power Systems (APVA 2002-2013).

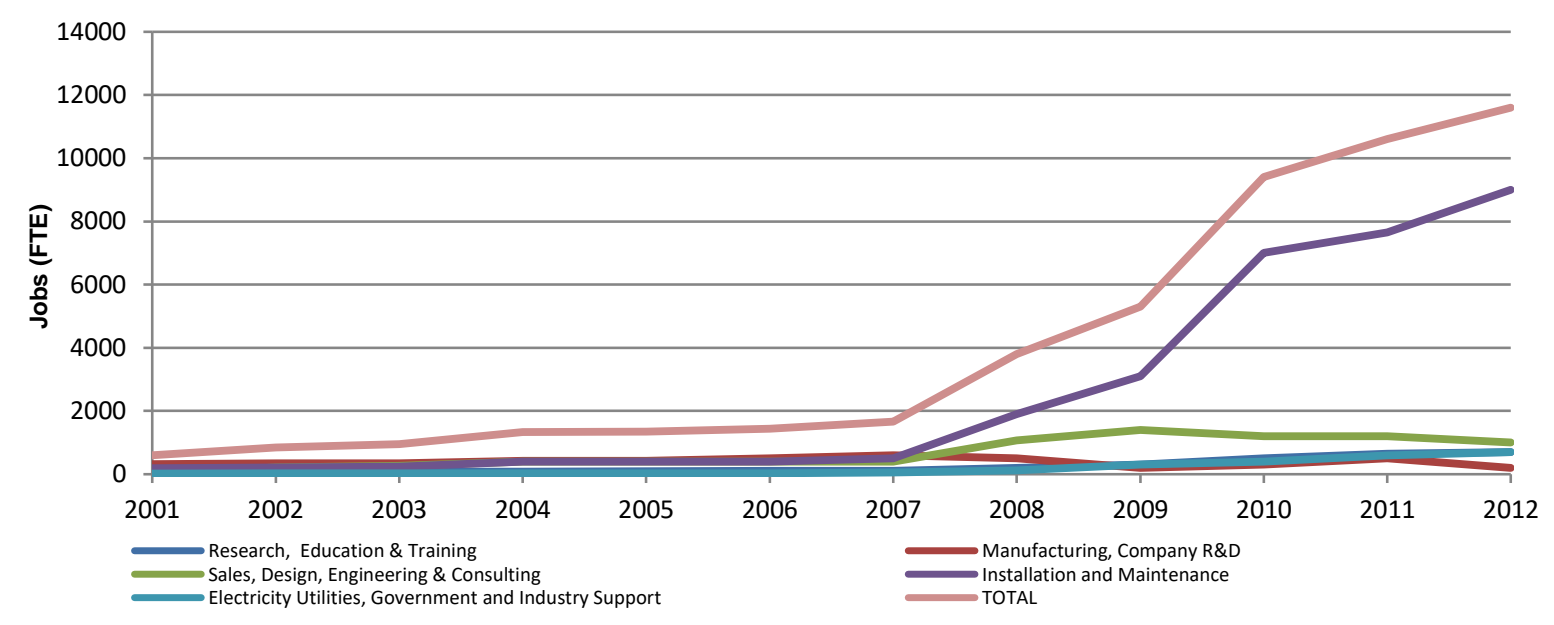

Figure 5. PV jobs 2001-2012 (adapted from APVA, 2002-13)

The total numbers of jobs, ranging from just 600 in 2001, up to 11,600 in 2012 includes all four PV sub-markets including off-grid domestic, off-grid non-domestic, grid connected centralised, and the focus of this study and most dominant sub-market of grid-connected residential PV. Approximately 78 per cent of these total jobs in 2012 are made up by installation and maintenance positions.

Evidence of this installation-and-maintenance-dominated domestic PV industry is shown in Figure 6. The number of accredited PV system installer and designers increased rapidly from just 108 in 2001, to 4,821 in 2012 to support the growing national demand for household PV systems. Accreditation has been administered by the Clean Energy Council since before the year 2000 when there were only 4 nationally accredited installers, and includes training through a registered training organisation, application for provisional accreditation, holding an electrical licence and sufficient public liability insurance. Transition from provisional accreditation is facilitated through the submission of as system installation 
Please reference the final published version, available at:

https://doi.org/10.1016/j.renene.2015.09.061

case study which is assessed by a technical expert prior to full accreditation being conferred (Clean Energy Council).

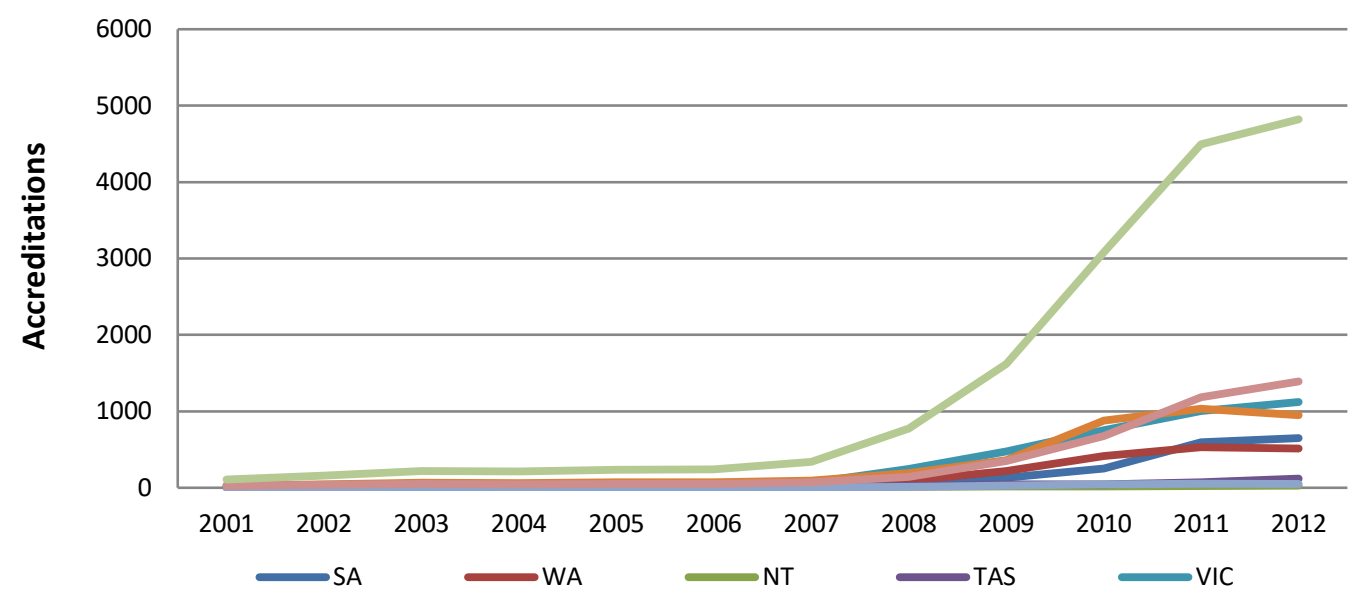

Figure 6. Accredited PV installers and designers 2001-2012 (CEC, 2013)

As demonstrated in Figure 7, from 2001 to 2007, a majority of PV industry jobs are attributed to off-grid systems. However, the year 2008 marks the beginning of the acceleration of the grid-connected residential distributed (domestic) PV market, and by 2012 this market accounts for approximately 95 per cent the amount of PV installed, and total PV jobs in Australia.

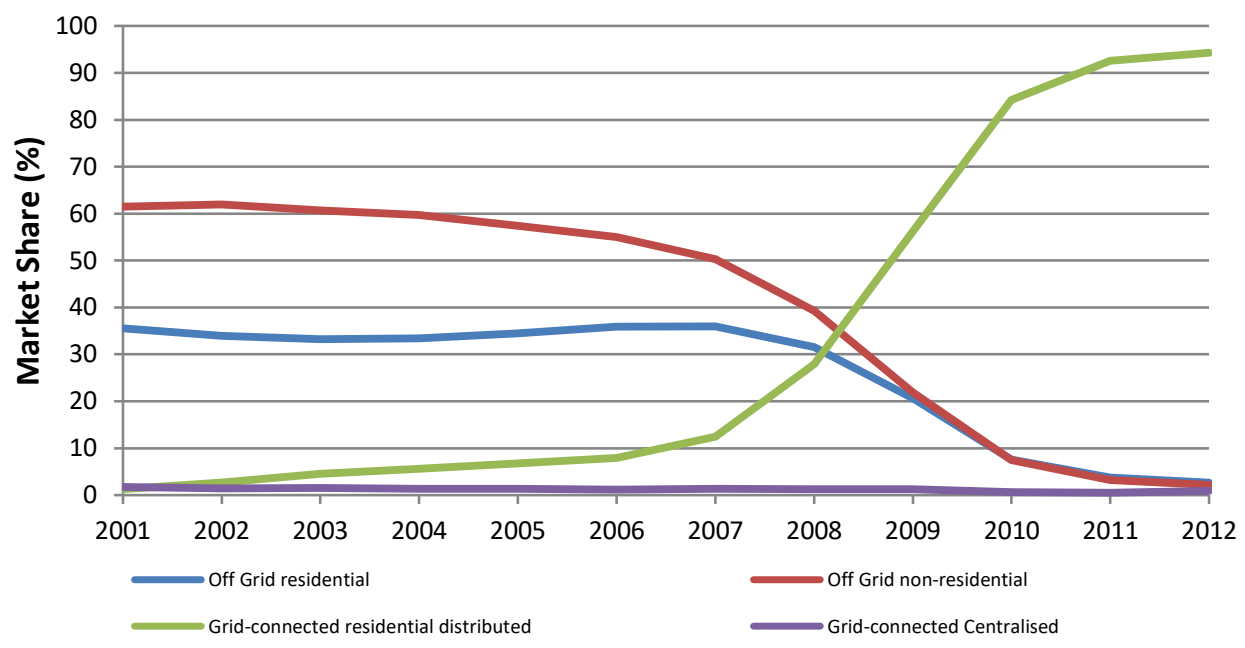

Figure 7. PV market share for four sub-markets 2001-2012 (APVA, 2013)

It is important to note that the size of these sub-markets are vastly different, the off-grid markets which were dominant from 2001-2007 had a combined size of approximately $30 \mathrm{MWp}$ in 2001, growing to approximately $66 \mathrm{MWp}$ by the end of 2007. During the same period, the grid-connected residential sub market accounted for between 3 and 15MWp, 
Please reference the final published version, available at:

https://doi.org/10.1016/j.renene.2015.09.061

however from 2008 onwards this sub-market grew rapidly, and by 2012 accounted for almost $2300 \mathrm{MWp}$, whilst the two off grid sub-markets grew to a combined total of just $118 \mathrm{MWp}$ (APVA, 2013).

\subsection{Price Performance with Market Maturity}

As a result of the rapid growth of the PV market in Australia, the installed price of Solar Systems between 1.5 and $3 \mathrm{~kW}$ decreased from a high of $\$ 15$ per watt installed in 2004 , to a low of $\$ 3$ per watt in 2012. Over the same period, the module price reduced from $\$ 8$ per watt to $\$ 1.80$ per watt due to global panel cost reductions (APVA, 2013). The number of overall jobs steadily increases as demonstrated in Figure 5, however after a sharp increase between 2008 and 2009, the total number of full time employees (directly related to PV) per MWp decreases from a high of 48 in 2008 to a low of approximately 11 by the year 2012 . The majority of these jobs are in installation and maintenance, reaching a high of 24 FTE/MWp in 2008, reducing each year to approximately 8.5 in 2012. Figure 8 and 9 show the reducing cost of PV modules and systems alongside the overall and installation FTEs per MW installed, and the number of systems installed from 2001-2012 (APVA, 2013, CEC, 2014).

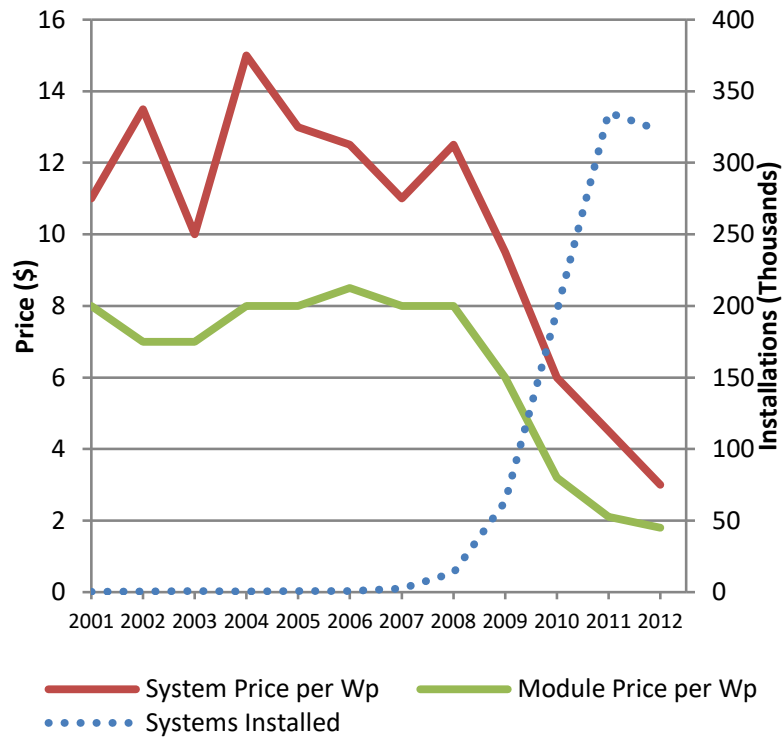

Figure 8. Systems installed and price

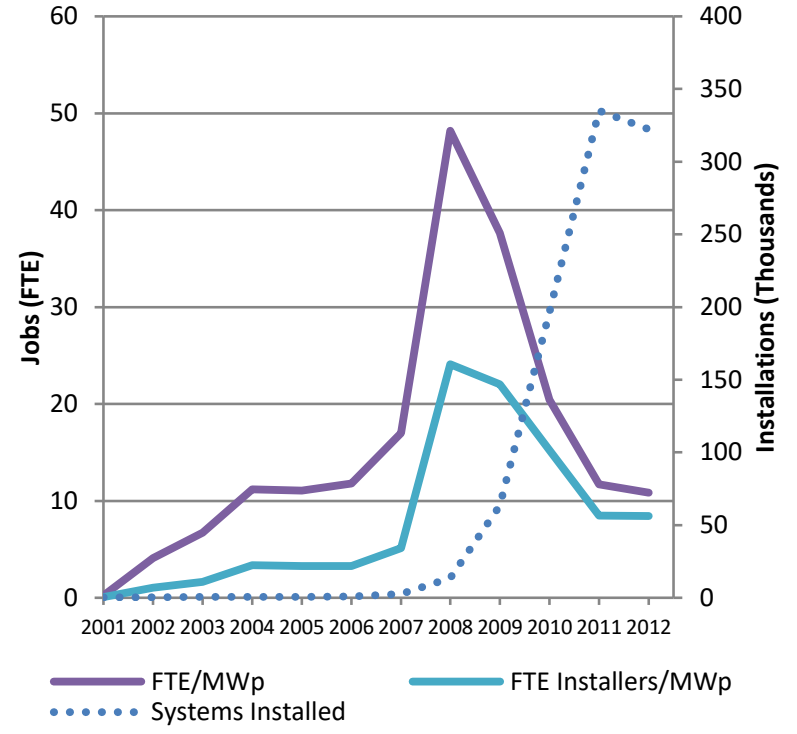

Figure 9. Systems installed and FTE/MWp

\subsection{Gross and Net FiT Income}

Australian states embraced many different FiT levels, across two distinct types; gross and net. A gross FiT rewards the household with the value of 100 per cent of electricity generated, irrespective of the usage pattern or time of use. Under a net FiT, the household is 
Please reference the final published version, available at:

https://doi.org/10.1016/j.renene.2015.09.061

only remunerated for electricity which is exported to the grid. Electricity used within the household during times of PV generation offsets the use of fossil fuels, and reduces the overall electricity bill, but only at the set electricity cost. Only excess electricity is rewarded at the (usually) higher FiT rate.

In New South Wales, the largest installer of PV under a gross FiT, an assessment of 30 minute generation data of 300 households (data provided by Ausgrid Network, 2011) was conducted to determine the average monthly PV generation, shown by season in Figure 10.
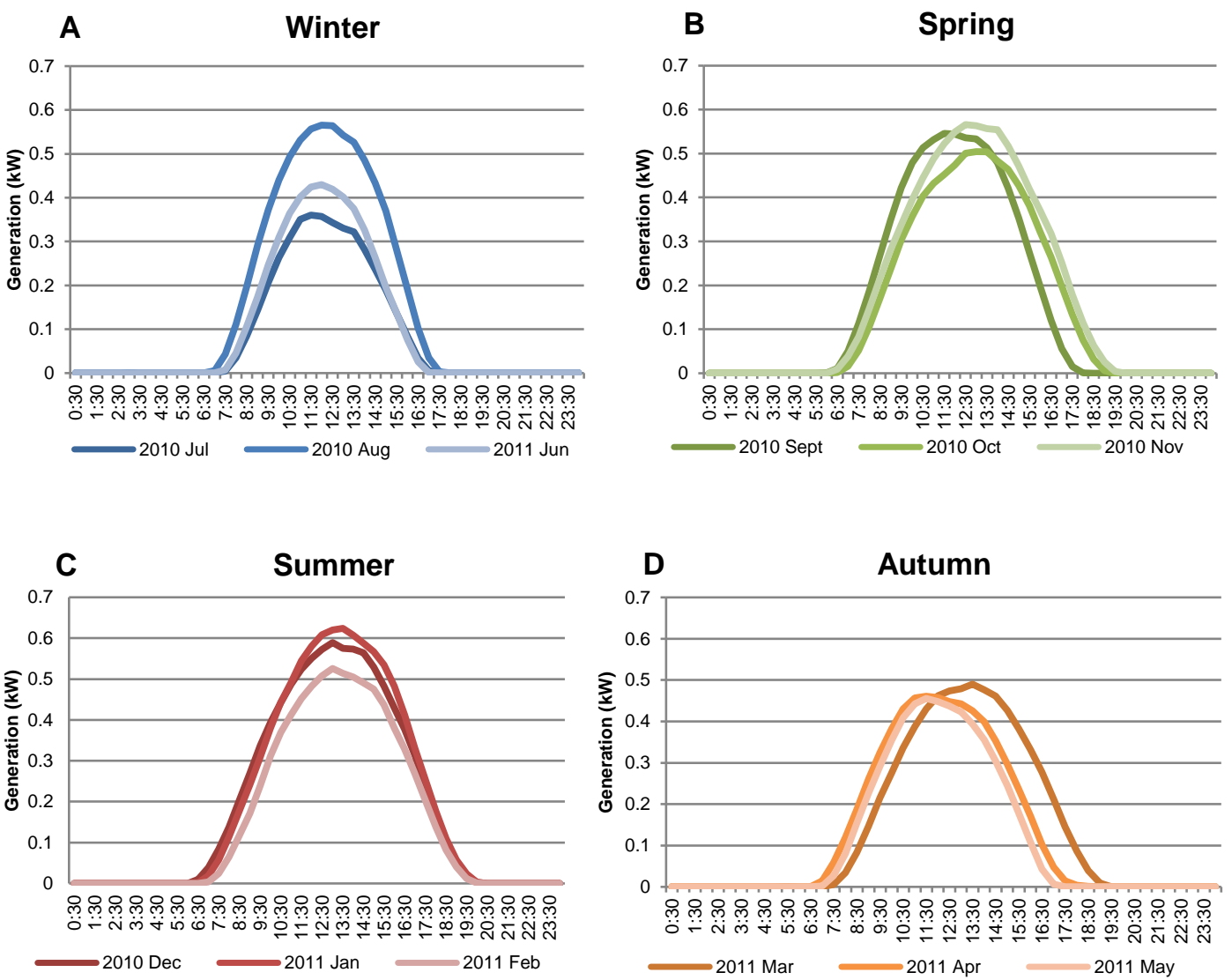

Figure 10. NSW average monthly PV generation per kWp

Analysis showed that $1 \mathrm{kWp}$ of installed PV generates between approximately $2 \mathrm{kWh}$ (July, winter) and 4.6kWh (January, summer), for an average of about 3.5kWh per day (Figure 11). The systems assessed are all eligible for the $60 \mathrm{c} / \mathrm{kWh}$ gross FiT. 
Please reference the final published version, available at:

https://doi.org/10.1016/i.renene.2015.09.061

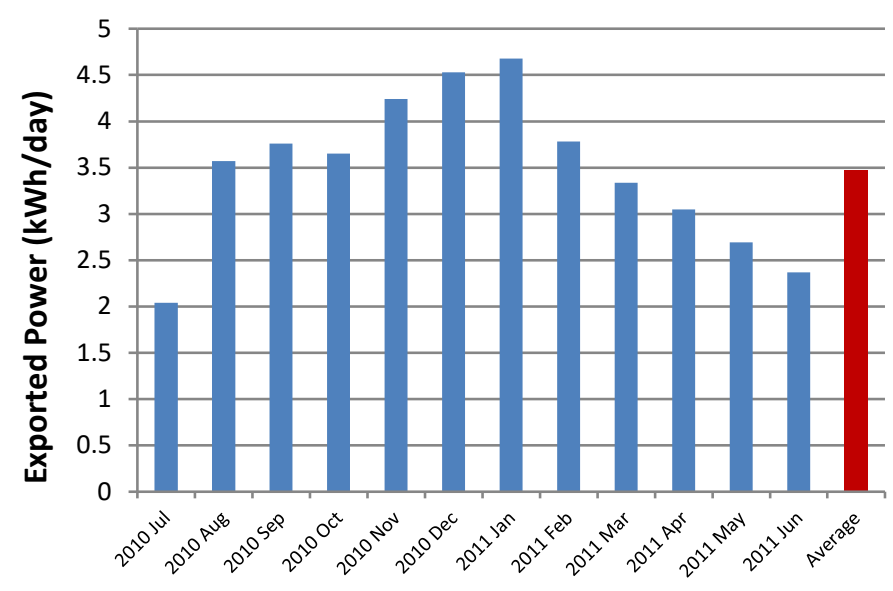

Figure 11. Average gross PV electricity exports

In contrast, under a net FiT, utilising the same group of households, during the same time period, with an average system size of $1.6 \mathrm{kWp}$, approximately 35 per cent of all annual PV generation is exported to the grid (IPART, 2012). Figure 12 demonstrates an example of the PV generation curve and electricity consumption pattern for June 2010.

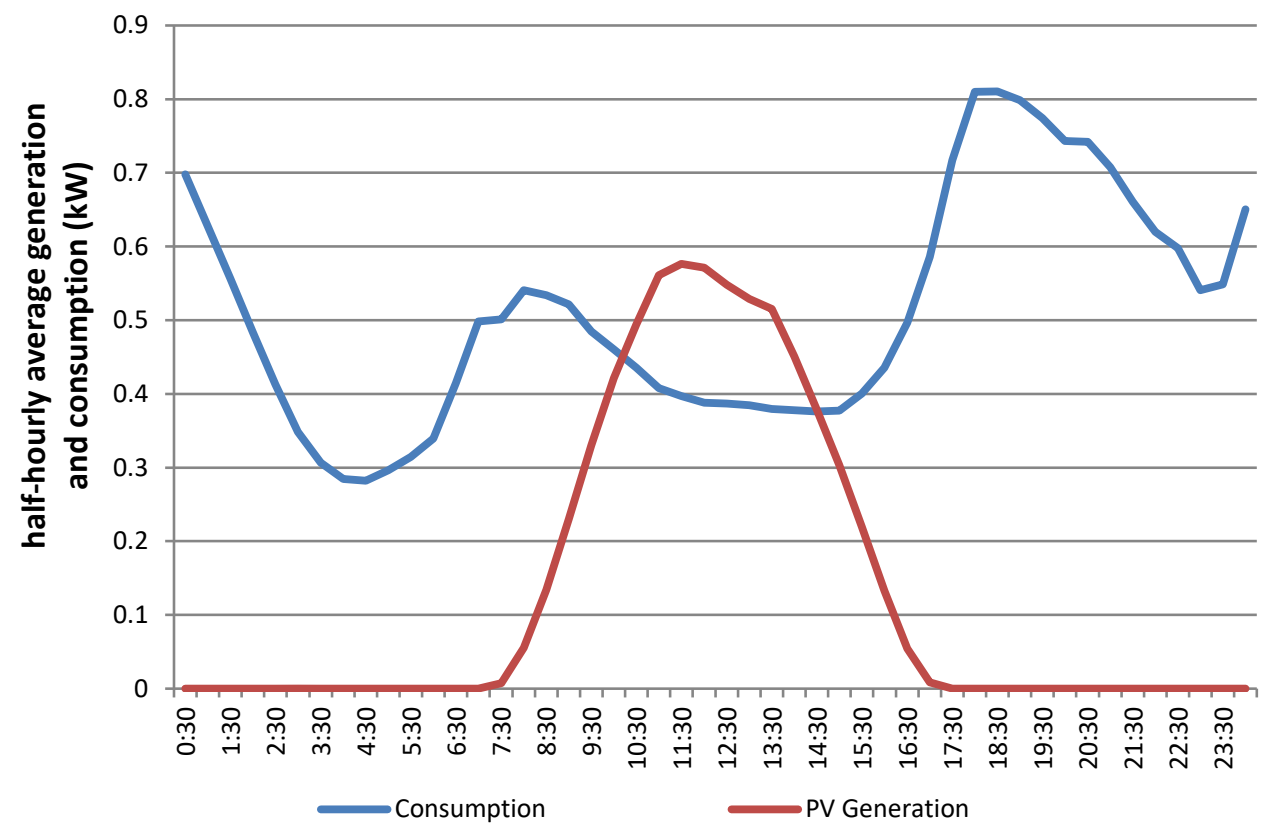

Figure 12. Example net PV export and electricity consumption (June 2010)

The net FiT, eventually introduced in NSW on 27 October 2010 was set at 20 cents, approximately equal to the retail cost of electricity.

Net and gross FiTs and FiT levels have markedly different impacts on the price of electricity. The nature and scale of these impacts are described within the analysis section. 
Please reference the final published version, available at:

https://doi.org/10.1016/j.renene.2015.09.061

\subsection{Environmental Benefits}

By the end of 2012, within the NEM states PV installations amounted to approximately 2019 MWp. Using assumed best case electricity generation scenarios for each of the state's PV totals (Clean Energy Council, 2011), an estimate of the best case MWh output for the NEM states can be determined, as outlined in Table 2.

Table 2. PV electricity generation 2012

\begin{tabular}{|c|c|c|c|}
\hline State & MWp Installed & MWh per MWp/Day & Total Generation (GWh)/Year \\
\hline SA & 339.61 & 4.2 & 520.6 \\
\hline TAS & 28.44 & 3.5 & 36.3 \\
\hline VIC & 405.81 & 3.6 & 532.2 \\
\hline NSW & 499.37 & 3.9 & 710.9 \\
\hline ACT & 28.14 & 4.3 & 44.2 \\
\hline QLD & 717.94 & 4.2 & 1100.6 \\
\hline NEM TOTAL & $\mathbf{2 0 1 9 . 3 1}$ & $\mathbf{4}$ & $\mathbf{2 9 4 4 . 8}$ \\
\hline
\end{tabular}

The total installed capacity of the NEM is $48,321 \mathrm{MW}$, meaning that residential PV accounts for some 4.2 per cent of this capacity, however the respective total generation within the NEM in 2012 was approximately 199 terawatt hours (AER, 2013), meaning that residential PV accounts for just under 1.48 per cent of total electricity supplied to the grid (under a best case scenario) during 2012.

Ignoring the embodied energy and lifecycle costs of PV panels, all of the electricity generated is carbon free, and where this offsets the consumption of fossil fuels, it represents a reduction in GHG of approximately 0.79t per MWh (Vivid Economics, 2013). 
Please reference the final published version, available at:

https://doi.org/10.1016/j.renene.2015.09.061

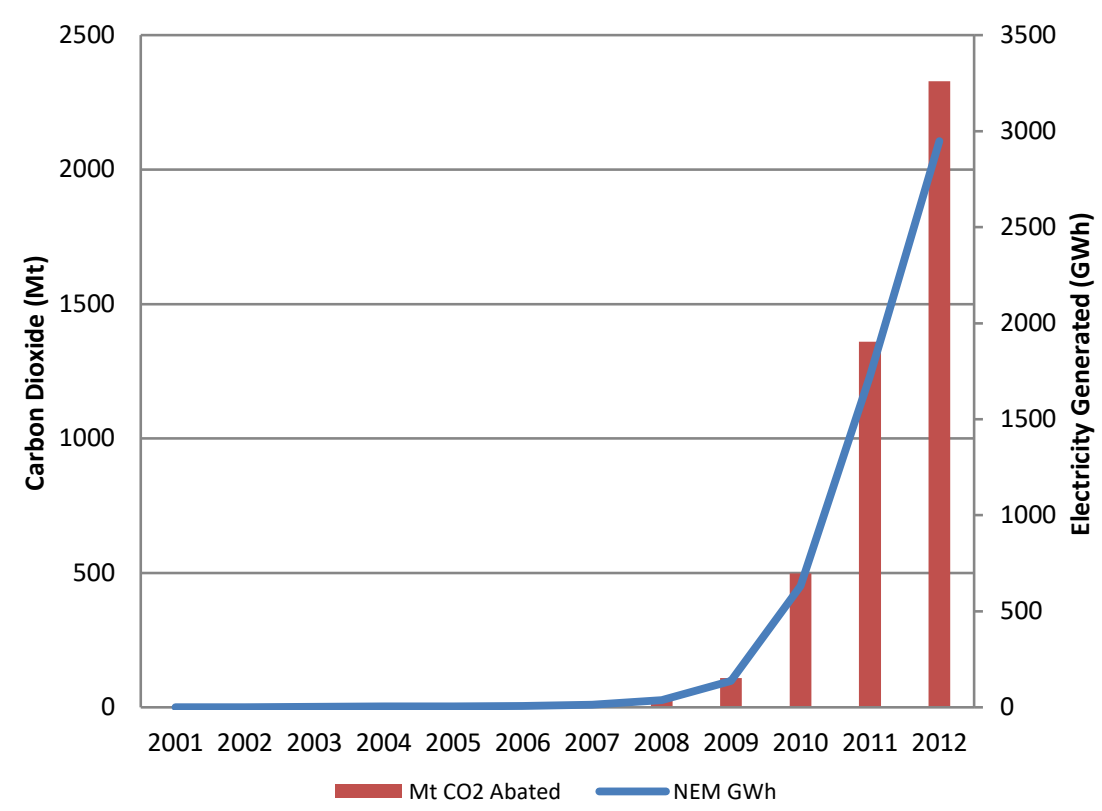

Figure 13. NEM residential PV electricity generation and $\mathrm{CO}_{2}$ reduction

Assuming that each yearly total amount of installed PV generates electricity over the same year, over the period of 2001-2012, the NEM States offset approximately $2330 \mathrm{Mt}$ of $\mathrm{CO}_{2}$ by 2012.This represents a carbon dioxide offset of just over 1.48 per cent of the total NEM emissions for 2012 , which are generated by a 75 per cent black and brown coal based network (AER, 2013).

\section{Analysis, Discussion and Implications}

Following from the above presentation of data which describes key outcomes in Australia during 2001-2012, this section analyses these outcomes and presents the key findings of Australian PV policy with regard to its successes and failures and any future ramifications resultant from these policy settings.

\subsection{Key policy drivers of PV installations}

Based on a comparison of REC and FiT outcomes as described in Section 2.1, it is reasonable to assume that the state-administered FiTs had a markedly higher effect on the deployment rate of residential PV, as evidenced by the rapid jump in installation rates from2008, the year FiTs were introduced.

Further, the high level of correlation with FiT levels and annual PV installation MWp within the NEM (as shown in Figure 14) suggests that investors in small-scale renewable energy are looking for long term support of their purchase, through income from the export of energy 
Please reference the final published version, available at:

https://doi.org/10.1016/j.renene.2015.09.061

to the grid, or reducing consumption of grid based electricity through efficient use of the electricity generated by their PV system. REC prices, although providing a point of sale rebate and reducing the overall cost of a PV system, do appear to provide a significant portion of the consumers' incentive for initial installation of PV at the household level. This premise is supported by the PV system size reduction observed in both WA and NSW in 2012, when their respective FiTs were removed (Figure 4).

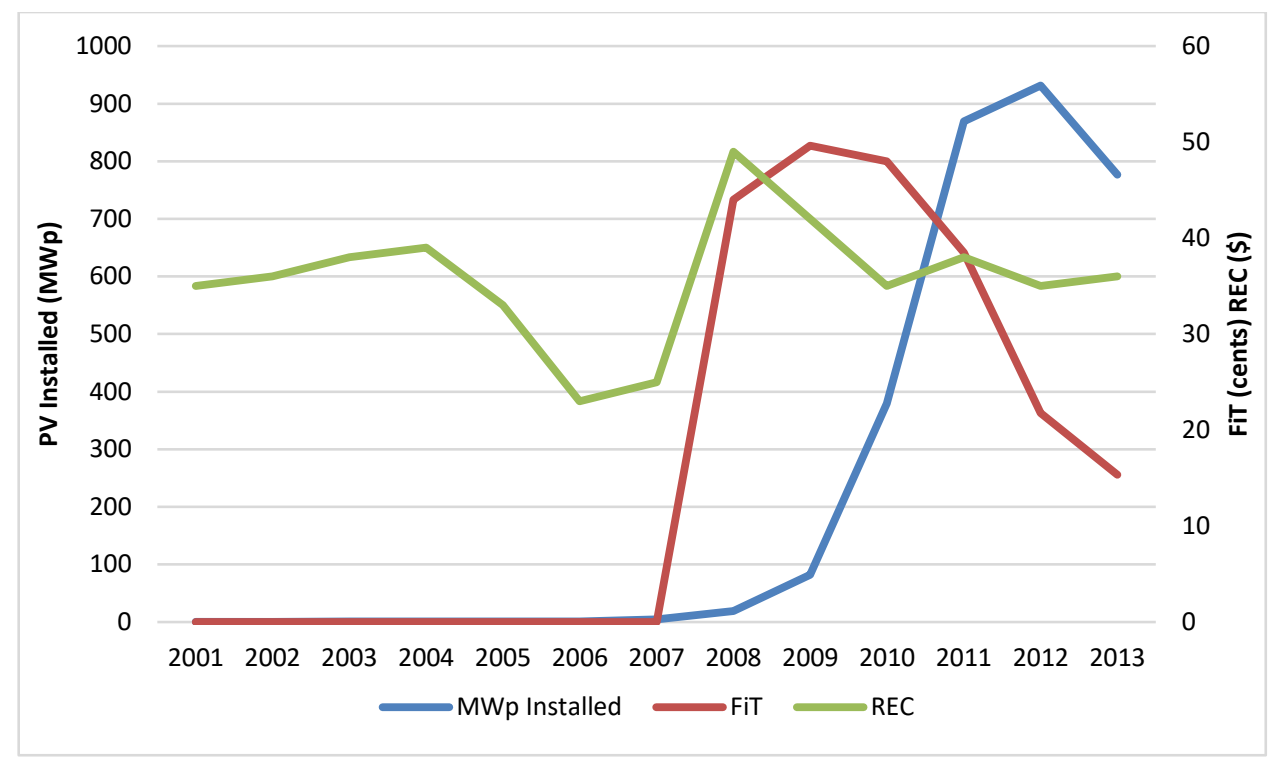

Figure 14. Correlation between FiT levels and annual PV installation (CEC, 2014)

As FiT levels decline, annual installation levels also decline. It is therefore reasonable to assume that a continued decline or indeed cessation of FiTs will lead to a further decline in annual installations. This decline will likely have a negative impact on industry development and employment levels.

\subsection{Employment and industry development}

Analysis of the direct PV employment data (CEC, 2014) (Figure 5) within Australia from 2001-2012 identifies that:

1. The employment market is dominated by installation and maintenance jobs (just under 78 per cent);

2. In support of these installation and maintenance jobs, the second largest industry group is sales, design, engineering \& consulting, making up almost 9 per cent of all FTEs; and, as a result 
Please reference the final published version, available at:

https://doi.org/10.1016/j.renene.2015.09.061

3. Manufacturing, company research and development account for less than 2 per cent of all PV jobs

Australia is clearly shown to be a country which exclusively imports household PV modules from other countries, and although limited research and development activity is occurring indigenously, this is not translating to the invigoration of local manufacturing. Further, as the vast majority (more than 86 per cent) of jobs within Australia are related to sales, system design, installation and maintenance of PV systems, these jobs are reliant on sustained installation rates, which are in turn dependent on sufficient FiT levels into the future.

In addition, Australia's directly employed 10.8 FTE per megawatt installed (Figure 9) is low when compared to that of Europe, although the directly employed figures are similar for system installers per MWp installed, Europe has significant FTE for module producers (3-7 FTE/MWp), Inverter and Balance of System manufacture (2-3 FTE/MWp respectively). The existence of these additional manufacturing jobs alone increases the required number of resultant administrative roles including sales and marketing (2-4 FTE/MWp). The total number of directly PV related jobs in Europe is up to 20 FTE/MWp (EPIA, 2012; excluding R\&D which can add an additional 1-2 FTE/MWp); approximately double that of Australia in 2012. The European Photovoltaic Industry Association (EPIA) estimates that for every direct PV job, two indirect jobs are created meaning that a contraction in the PV industry will have significant run-on effects for external support industries.

This effect on employment numbers may be a result of the different strategic purposes of renewable energy targets, which in Australia are somewhat passive and aim only for the "promotion of the renewable energy industry", whilst countries like Germany have a more active stance which includes the national objective of "economic prosperity through jobs and innovation" for their renewable energy industry (WWF and WRI, 2013).

With FiTs being reduced and REC multipliers being phased out, direct PV FTE numbers are also declining. Further, PV jobs are vulnerable to contraction of the industry at differing rates for different type of jobs. The main employer in Australia, installation and maintenance is considered relatively safe, as employees in this stream have transferrable skills (electrical contractors). It is estimated that 75 per cent of these employees could be relocated across other industries. The most vulnerable jobs are wholesalers and retailers, of which only 25 per cent are expected to be able to transition to alternative activities (Intelligent Energy Systems, 2012). 
Please reference the final published version, available at:

https://doi.org/10.1016/j.renene.2015.09.061

\subsection{Market Development and Maturity}

The maturing of the Australian residential PV market has important directly observable impacts. Firstly, over time, even as installation rates increase year on year, following an initial spike when the FiT is introduced in 2008 the jobs to MWp ratio declines significantly each year before stabilising around 2011-12. Further, over time installation and maintenance jobs account for an ever increasing percentage of total jobs (Figure 9).

Secondly, this installation and maintenance centric employment market develops over time, through an increasingly skilled workforce, economies of scale, and a decrease in profitability, demonstrated by the shrinking gap between module cost and system cost in Figure 15.

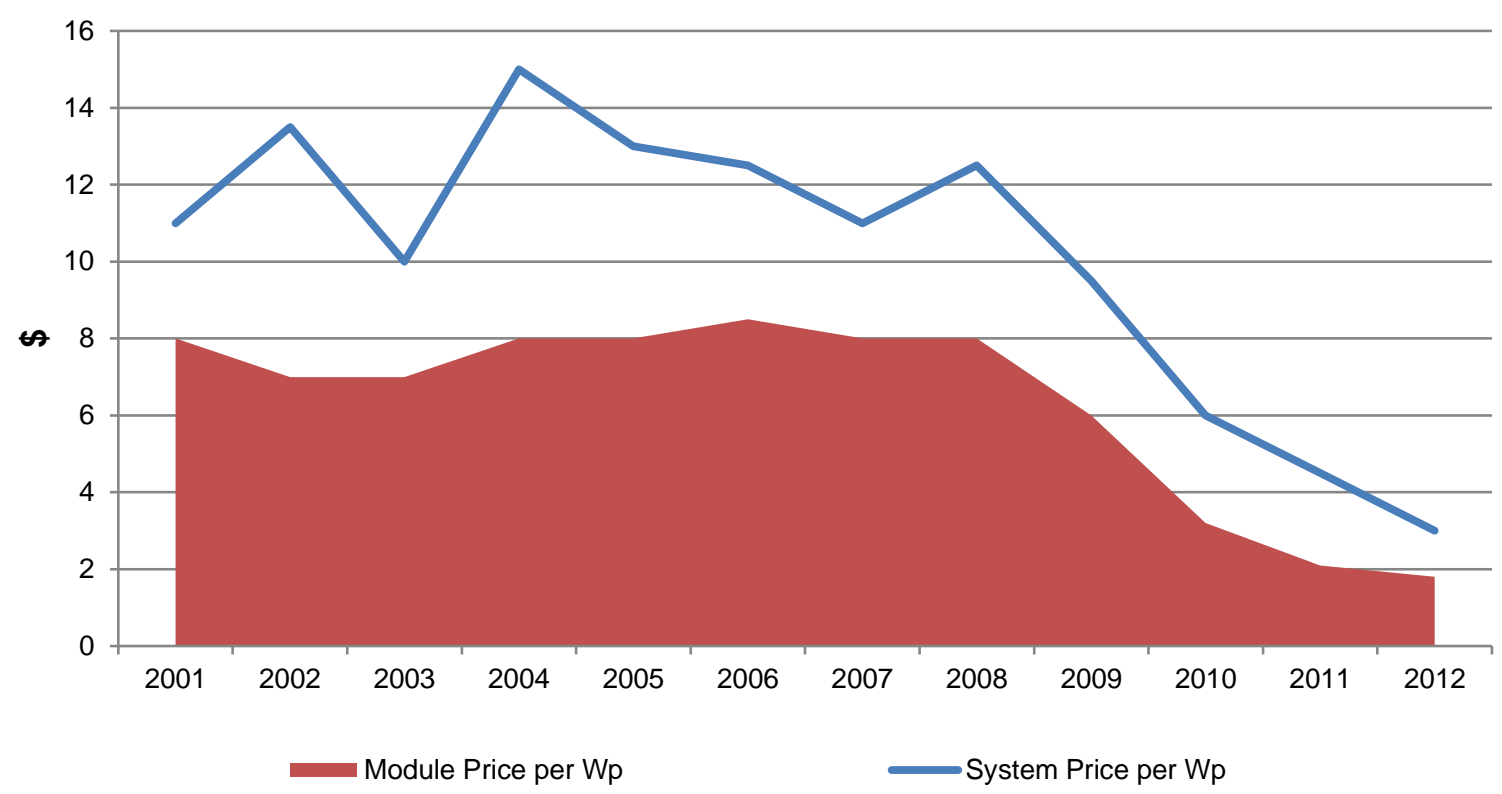

Figure 15. Comparison of PV System and Module Prices

The maturing of the installation workforce is clearly demonstrated in Figure 16 which shows the declining trend of per system profitability (system price minus module price) as the number of systems installed increases. 
Please reference the final published version, available at:

https://doi.org/10.1016/j.renene.2015.09.061

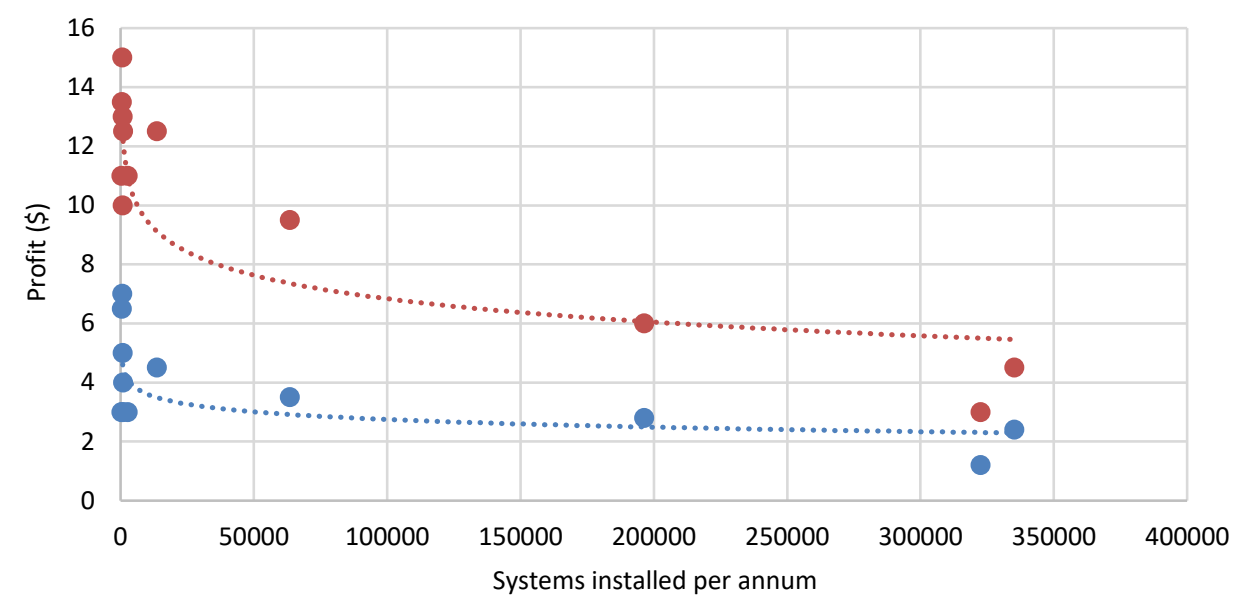

- Profit per Wp - System Price per Wp

Figure 16. PV system installations; price and profitability trends

Similarly, as system installations increase, and the commercialisation of PV installation occurs, to coincide with the introduction of the FiT in 2008, a rapid reduction in the number of installation and maintenance FTEs per MWp installed occurs as shown in Figure 17.

Installers per MWp are divided into two groups; a pre-commercialisation group showing FTE per MWp prior to the introduction of the FiT, when installation numbers were insignificant, and, a post-commercialisation group to demonstrate the impact of rapid PV system deployment on installation FTEs per MWp.

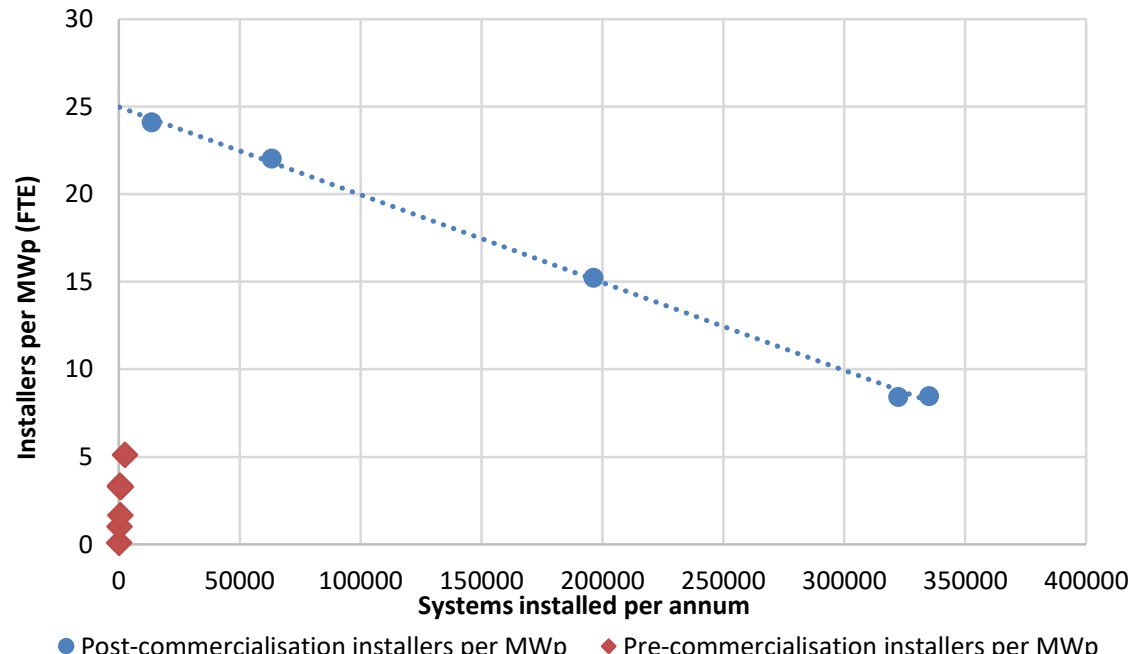

Figure 17. Market maturity impact on PV installation and maintenance workforce

A unique factor of the Australian PV market is that the majority of learning is associated with installation and maintenance, over 77 per cent of all PV jobs are in this industry group, and 
Please reference the final published version, available at:

https://doi.org/10.1016/j.renene.2015.09.061

in contrast to European markets, no learning is achieved in manufacturing. Reducing module costs are due to exogenous factors. Learning by doing is shown to be the key endogenous factor in Australia which is reducing the number of installation and maintenance FTEs required per $\mathrm{MWp}$.

Additionally, some system inefficiencies were overcome over time. For example, the large number of per MWp FTEs employed between 2008 and 2009 consisted of between 50 and 60 per cent installation and maintenance jobs, with over a quarter of all jobs accounted for by sales, design, engineering and accounting positions. This balance changed markedly in 2010, with sales, design, engineering and accounting jobs halving to account for under 13 per cent of the total, to eventually account for less than 9 per cent by 2012 (Figure 18).

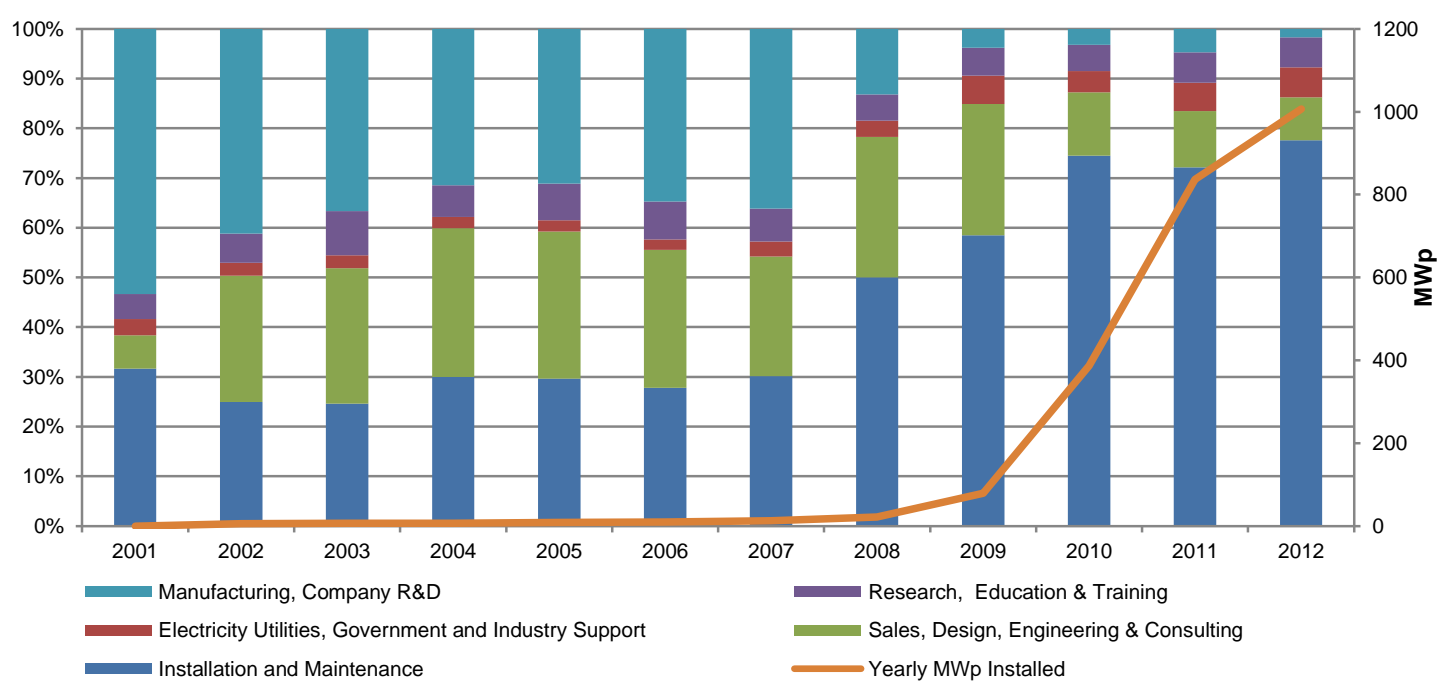

Figure 18. PV industry percentage of employees

This suggests that the transition to a FiT regime and the associated administrative burden and learning period required an additional employment base until learnings were made and efficiencies achieved. It is reasonable to assume that the incorporation of the FiT, adding an additional layer of government approval and administration (State) exacerbated this employment boom. The introduction of the FiT lead to an ever reducing percentage of manufacturing jobs, with no significant growth in FTE numbers; in fact manufacturing jobs declined to their lowest in 2012, even less than as at 2001 levels. Figure 19 outlines the FTE numbers for each industry grouping (except for installation and maintenance), and compares their growth with annual PV MWp installations. During the period of the FiT, each industry group shows an increase in FTEs each year, except for manufacturing and R\&D and sales and design, engineering and consulting jobs, which, after a brief spike in 2008-09 
Please reference the final published version, available at:

https://doi.org/10.1016/i.renene.2015.09.061

reduced to below 2008 levels by 2012 further demonstrating the streamlining within this industry sector.

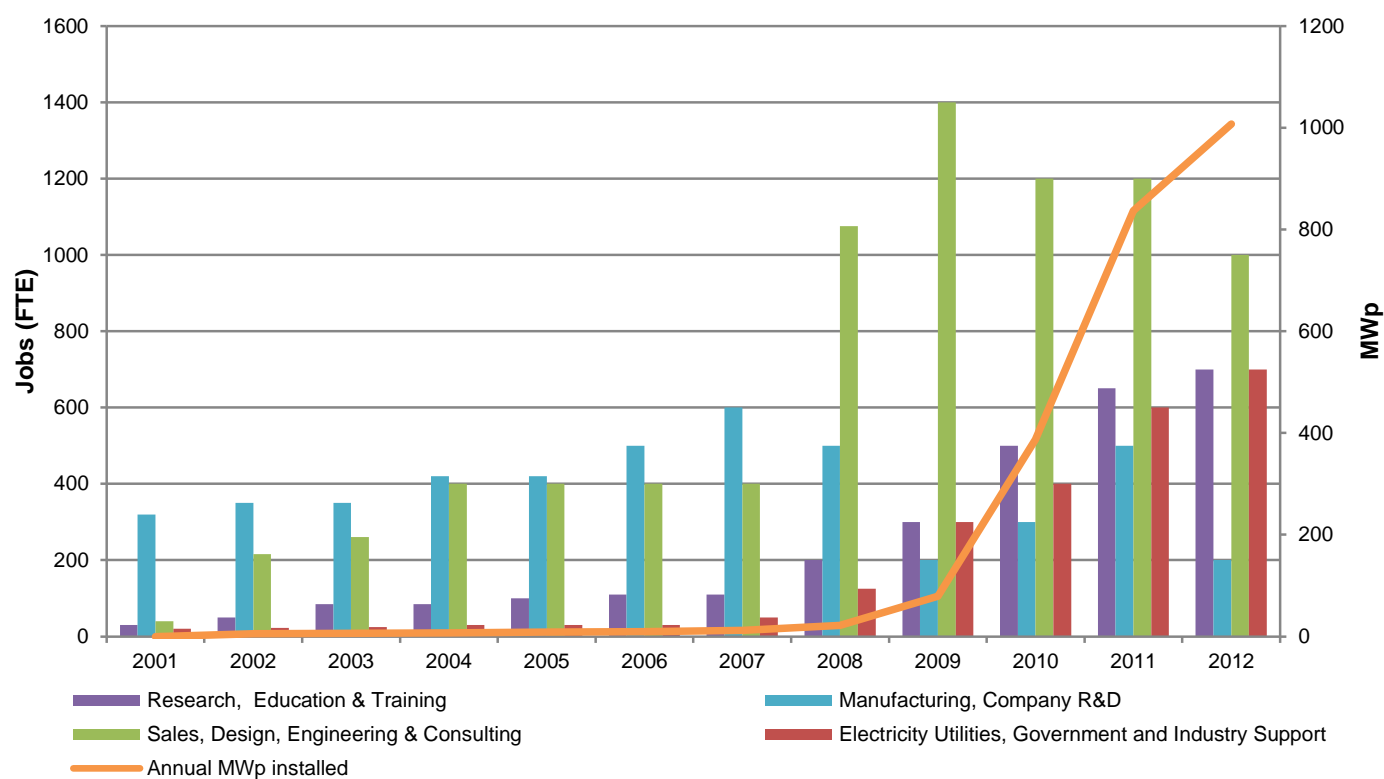

Figure 19. FTE growth by industry group

\subsection{FiT-based income and impact on electricity prices}

The assessment of net and gross FiT regimes within NSW, as described in Section 2.4, allow for a determination of the overall cost of each type of FiT regime, and also gives a basis from which to estimate the overall impact on electricity prices within the investigated jurisdictions.

In the case of a gross FiT, as administered in NSW from 1 January to 27 October of 2010, the income per kWp installed is approximately $\$ 760.00$ per annum at 60 cents per $\mathrm{kWh}$ exported. Assuming that all of the 149.19MWp installed in 2010 was eligible for this FiT (a reasonable and conservative assumption, as systems had only to be purchased by the end date of 27 October - installation could occur later (NSW Trade and Investment, 2013)), the total FiT payments would amount to $\$ 113.4$ million dollars in 2010 . Expressed as a cost per household, this comes to approximately $\$ 40.50$ for every household within NSW for the year 2010 (household numbers derived from ABS Data, 2010).

The average annual electricity consumption per household in NSW is $7082 \mathrm{kWh}$ (ACIL Tasman, 2011), or $19.4 \mathrm{kWh}$ per household per day. In 2010-11 retail tariffs for electricity were approximately $19 \mathrm{c} / \mathrm{kWh}$ (Industry and Investment NSW, 2010). The average household bill (excluding supply charges) was approximately $\$ 1345$ per annum. In Australia, 
Please reference the final published version, available at:

https://doi.org/10.1016/j.renene.2015.09.061

the cost of FiT payments are firstly borne by electricity retailers and then passed onto residential customers through increased electricity bills.

A comparison of gross and net FiT impacts, using data from NSW in 2010 under 3 FiT price scenarios is shown in Table 3.

Table 3. FiT setting comparison based on 2010 NSW PV generation data.

\begin{tabular}{|c|c|c|c|c|c|c|}
\hline Scenario & $\begin{array}{c}\text { FiT } \\
\text { type }\end{array}$ & $\begin{array}{c}\text { FiT price/ } \\
\text { kWh }\end{array}$ & $\begin{array}{c}\text { Solar } \\
\text { output/ } \\
\text { kWp }\end{array}$ & $\begin{array}{c}\text { Exported } \\
\text { to grid/ } \\
\text { kWp }\end{array}$ & $\begin{array}{c}\text { FiT } \\
\text { payment/ } \\
\text { kWp }\end{array}$ & $\begin{array}{c}\text { Impact on } \\
\text { electricity bill per } \\
\text { household p/a }\end{array}$ \\
\hline $\mathbf{1}$ & Gross & $60 \mathrm{c}$ & $1267 \mathrm{kWh}$ & $1267 \mathrm{kWh}$ & $\$ 760$ & $\$ 40.50$ or $3.01 \%$ \\
\hline $\mathbf{2}$ & Net & $60 \mathrm{c}$ & $1267 \mathrm{kWh}$ & $443 \mathrm{kWh}$ & $\$ 266$ & $\$ 14.17$ or $1.05 \%$ \\
\hline $\mathbf{3}$ & Net & $20 \mathrm{c}$ & $1267 \mathrm{kWh}$ & $443 \mathrm{kWh}$ & $\$ 89$ & $\$ 4.74$ or $0.35 \%$ \\
\hline
\end{tabular}

Scenario 1 shows that under a gross FiT, as was in place in NSW in 2010, the annual impact on electricity bills is a significant 3 per cent increase. The introduction of a net FiT, even at the same generous rate as the preceding gross FiT, as in Scenario 2, reduces the burden on non-solar households by approximately 65 per cent, in the above example reducing the overall impact to a 1 per cent per annum increase in average sized electricity bills. This reduction in electricity bill percentage increase is directly proportional to the percentage of annually exported PV generated electricity. Scenario 3 demonstrates the reduced electricity bill impacts under a net FiT with a reduced FiT price of 20 cents per kWh (as occurred in NSW on 27 October 2010).

The impact of gross and net FiTs on electricity prices within NSW are cumulative and ongoing; Analysis provided by the Independent Pricing and Regulatory Tribunal describes how PV uptake has often exceeded levels anticipated by governments, and this can exacerbate the cost of FiT schemes (IPART, 2012). Complementary to this study's findings, IPART estimates that the costs incurred by retailers through FiT payments and REC purchases (not considered in this study, resultant from the SRES) added approximately 6 per cent to electricity prices in NSW during 2011, adding credence to the figure estimated under the gross FiT scenario.

Although all households experience the electricity bill increase due to PV FiT costs, a major equity issue of the FiT is the unequal sharing of costs between solar and non-solar households. In the above example of the 2010 gross FiT impact, approximately 70,000 solar households are deriving a benefit from the FiT, whilst the remaining 2.7 million non-solar households who do not receive FiT payments are required compensate them. Indeed under the gross FiT scenario, for each kWp of PV installed, the solar household receives a benefit of approximately $\$ 720$ (value of exported PV electricity minus the increase in electricity bill), 
Please reference the final published version, available at:

https://doi.org/10.1016/j.renene.2015.09.061

whilst households without PV are paying $\$ 40.50$ per annum. This represents a cross subsidisation, being paid for by a majority of households, for the benefit of just 2.5 per cent of households which were able to install PV during 2010.

In an attempt to remedy these emerging impacts, FiTs (with the exception of Tasmania which maintained a 1 for 1 FiT to electricity price ratio throughout 2008-2012) were unanimously reduced between 2008 and 2012 in all NEM jurisdictions. Additionally, the REC multiplier was removed six months ahead of schedule, to lower the impact of the high uptake of PV on electricity costs for homes and businesses (Ministerial Media Release, Minister for Climate Change and Energy Efficiency, Minister for Industry and Innovation, 15 Nov 2012) and to ease pressure on electricity prices.

The costs incurred by each household due to the FiT also yield a social benefit of reduced $\mathrm{CO}_{2}$ emissions, shared equally across the NEM grid through a displacement of fossil fuel generation. The scale of these emission reductions is discussed below.

\subsection{Environmental Benefits Comparison}

An investigation of a best case scenario for PV generation within the NEM has shown that although residential PV accounts for approximately 4.2 per cent of the installed generating capacity within the NEM, it produces less than 1.5 per cent of the electricity consumed. This means that for every MWp of PV installed within the NEM we can expect a reduction in $\mathrm{CO}_{2}$ of approximately 1.15 tonnes per annum.

The two alternative major sources of grid connected renewable energy within the NEM are wind power, prominently in South Australia, and hydroelectricity which is concentrated in the Snowy Mountains of NSW and throughout Tasmania.

Wind power accounts for 5.4 per cent of capacity within the NEM, but due to intermittency only accounts for 3.4 percent of output. Hydroelectric generation accounts for 17 percent of capacity and 9 per cent of output. Based on these figures, wind power offsets approximately 2 tonnes of $\mathrm{CO}_{2}$ per MW installed, per annum. Hydroelectric generation offsets approximately 2.2 tonnes per MW/annum (AER, 2013).

Although these technologies are at differing levels of maturity, and require differing levels of support, at their current level of development and deployment, it is clear that household PV is not as effective in reducing $\mathrm{CO}_{2}$ as either wind power or hydroelectric generation as demonstrated in Figure 20. 
Please reference the final published version, available at:

https://doi.org/10.1016/j.renene.2015.09.061

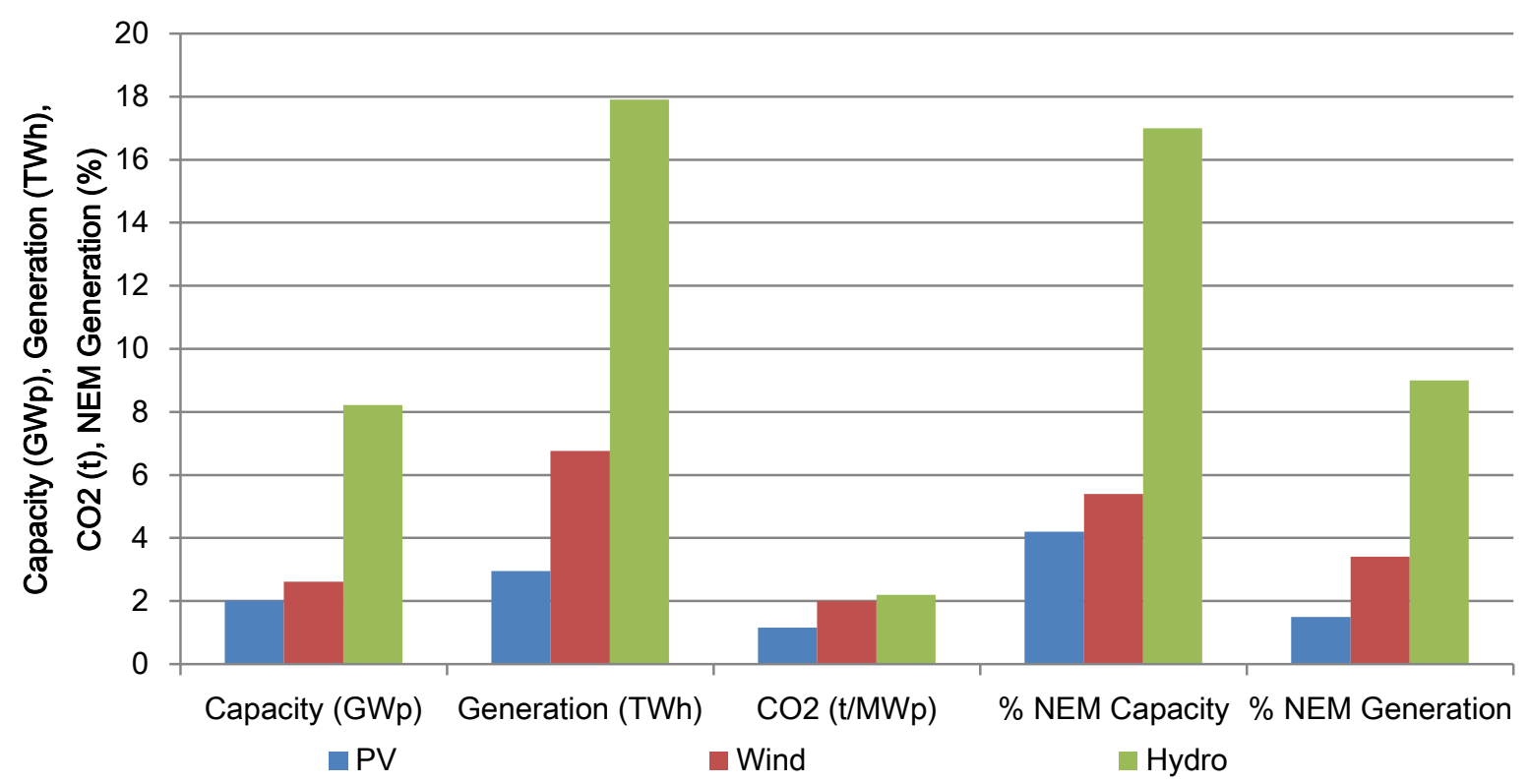

Figure 20. Capacity, generation and $\mathrm{CO}_{2}$ reduction for renewable energy sources within the NEM

These figures do not consider life cycle GHG emissions for each technology but show that wind and hydro, produce more electricity and reduce a greater amount of $\mathrm{CO}_{2}$ per $\mathrm{MWp}$ installed. It is encouraging to note that in Australia, that the most efficacious (from a $\mathrm{CO}_{2}$ reduction per MWp point of view) renewable energy sources are also the most prolific. One risk of a sustained high subsidisation rate of small scale renewable energy such as PV is that a less efficacious form of renewable energy may be over-represented in the renewable energy mix.

\section{Conclusion}

This paper analysed five criteria: installation rates and impetus, employment, market maturity effects, gross and net FiT impacts and environmental outcomes to determine the successes, failures and ongoing impacts of Australian residential PV policies, when measured against the stated goals (in Section 1.1) of the Small-scale Renewable Energy Scheme within the Australian Renewable Energy Target (RET).

This paper has identified that the Australian Government was largely successful in meeting its first goal of significant new additional renewable energy. Through the addition of more than 2300MWp of residential PV from 2001-2012, a moderate reduction in electricity sector greenhouse gas emissions was achieved through the displacement of 1.5 per cent of fossil fuel based electricity generation by 2012 . However, this $\mathrm{CO}_{2}$ reduction is overshadowed by the contributions of wind and hydro power, both in terms of tonnes per $\mathrm{MWp}$, and overall displaced emissions meaning that even with significant federal and state government 
Please reference the final published version, available at:

https://doi.org/10.1016/j.renene.2015.09.061

support over a significant period, residential PV was not shown to be an ideal technology choice from an electricity generation or $\mathrm{CO}_{2}$ reduction viewpoint. Further, as small-scale RECs were multiplied over a period of three years, investment into large scale RE was reduced, in turn reducing the generation and $\mathrm{CO}_{2}$ reduction capacity of the NEM's renewable energy mix, and reducing the efficient achievement of Kyoto Protocol greenhouse gas reduction goals.

With regard to promotion of the renewable energy industry, results of analyses show varied outcomes including irregular, and in all measured criteria, unsustained growth. This lead to a waxing and waning of industry groups, and an underdeveloped renewable energy industry dominated by installation and maintenance jobs yet almost devoid of manufacturing activity. These outcomes can largely be attributed to inconsistent policy settings with varying levels of State and Federal Government support over time, including REC multipliers which were reduced ahead of planned timelines, and the introduction of over generous FiT regimes, followed by rapid reduction and in some cases cessation of this support mechanism. The stated goal of long term support of renewable energy industries has not been demonstrated by this study, and indeed manufacturing and company research and development employment numbers are lower than 2001 levels, and sales and installation employment numbers are faltering due to this lack of support.

In addition to identifying the successes and failures of residential solar policy in Australia, policy impacts were also explored. Result of analysis over time suggest that FiTs influenced installation rates more than RECs, and were responsible for the sharp increase in installations post 2008 and also responsible for subsequent reductions in installation rates as FiTs tapered off or were removed. The differing impact levels of gross and net FiTs was explored to determine that a gross FiT is a more expensive approach than a net FiT to the deployment of PV, as all electricity generated is eligible for the tariff, and under a gross FiT there is no incentive for households to modify their electricity usage habits, by either reducing electricity consumption, or shifting the time of their consumption, as is expected under a net FiT arrangement. Additionally, FiTs caused inequitable societal outcomes, most pronounced of which is the significant cross subsidisation from non-solar households to solar households in the form of increased electricity bills for non-participants.

As PV installations increased in Australia, it was observed that system prices and profitability of installed systems also reduced leading to a commensurate decrease in the installation and maintenance workforce per MW installed. Results showed that although Australia has similar installation and maintenance job numbers per MW installed as observed in Europe, 
Please reference the final published version, available at:

https://doi.org/10.1016/j.renene.2015.09.061

overall, only half as many people per MW installed are employed due to an almost complete lack of manufacturing or company research and development within the Australian PV industry.

Whilst this paper discusses the successes, failures and impacts of Australian residential solar PV policy from 2001-2012, the potential inequity of these policies warrants further research, considering not only the impact variation between high and low socioeconomic status groups but also factors such as support of alternative $\mathrm{CO}_{2}$ reducing technologies, dwelling type limitations and policy educational impacts. 
Please reference the final published version, available at:

https://doi.org/10.1016/j.renene.2015.09.061

\section{References}

Access Economics. 2008. The Economics of Feed-in Tariffs for solar PV in Australia. Report for the Clean Energy Council, November, 2008.

ACIL Tasman. 2011. Electricity Bill Benchmarks for residential customers, report for the Australian Energy Regulator. December 2011.

Aurora Energy. 2014. Solar Energy. <www.auroraenergy.com.au/your-home/solarenergy>, 22 April 2014.

Ausgrid Electricity Network. 2011. Solar home electricity data - 1 July 2010 to 30 June 2011. <www.ausgrid.com.au/Common/About-us/Sharing-information/Data-toshare/Solar-household-data.aspx>, 27 February, 2014.

Australian Bureau of Statistics (ABS). 2010. NSW State and Regional Indicators, Dec 2010: Family and Community.

Australian Energy Market Operator (AEMO). 2014. Aggregated Price and Demand Data Files. <http://www.aemo.com.au/Electricity/Data/Price-and-Demand/Aggregated-Priceand-Demand-Data-Files>, 6 May, 2014.

Australian Energy Regulator (AER). 2013. State of the Energy Market 2013, 20-26.

Australian Government. (2001). Renewable Energy (Electricity) Act 2001, Section 3. Canberra.

Australian Photovoltaic Association (APVA). 2013. PV in Australia 2001-2012. Reports prepared for the International Energy Agency PV Power Systems Programme.

Bahadori, A. Nwaoha, C. Zendehboudi, S. Zahedi, G. 2013. An overview of renewable energy potential and utilisation in Australia. Renewable and Sustainable Energy Reviews $21,582-589$.

Buckman, G. Diesendorf, M. 2010. Design limitations in Australian renewable electricity policies. Energy Policy 38, 3365-3376.

Byrnes, L. Brown, C. Foster, J. Wagner, L. 2013. Australian renewable energy policy: Barriers and challenges. Renewable Energy, 60, 711-721.

Cherrington, R. Goodship, V. Longfield, A. Kirwan, K. 2013. The feed-in tariff in the UK: A case study focus on domestic photovoltaic systems. Renewable Energy 50, 421-426.

Clean Energy Council. 2011. Consumer guide to buying household solar panels. Volume 14, pg. 4.

Clean Energy Council (CEC). 2013. Clean Energy Australia Report 2012.

Clean Energy Council (CEC). 2014. Clean Energy Australia Report 2013. 
Please reference the final published version, available at:

https://doi.org/10.1016/j.renene.2015.09.061

Clean Energy Regulator. 2012. The Small Scale Renewable Energy Scheme. $<$ http://ret.cleanenergyregulator.gov.au/About-the-Schemes/Small-scale-RenewableEnergy-Scheme--SRES-/about-sres>, 16 May 2013.

Clean Energy Regulator. 2012. Solar credits phased out. <http://ret.cleanenergyregulator.gov.au/Latest-Updates/2012/November/3>, 22 November 2012.

Cludius, J. Forrest, S. MacGill, I. 2014. Distributional effects of the Australian Renewable Energy Target (RET) through wholesale and retail electricity impacts. Energy Policy, In Press.

Department of Industry, Innovation, Climate Change, Science, Research and Tertiary Education. (2011). Enhance Renewable Energy Fact Sheet. <http://www.climatechange.gov.au/reducing-carbon/renewable-energy/renewableenergy-target/enhanced-renewable-energy-target>, 16 May 2013.

Department for Manufacturing, innovation, Trade, Resources and Energy (DMITRE), 2013. <www.sa.gov.au/topics/water-energy-and-environment/energy/energy-supply-andsources/renewable-energy-sources/solar-energy/solar-photovoltaic-systems/solar-feedin-scheme>, 16 May 2013.

Department of State Development, Business and Innovation (DSDBI), 2014. Closed feed-in tariff schemes. <www.energyandresources.vic.gov.au/energy/environment-andcommunity/victorian-feed-in-tariff-schemes/closed-schemes>, 11 February 2014.

Effendi, P. Courvisanos, J. 2012. Political aspects of innovation: Examining renewable energy in Australia. Renewable Energy 38, 245-252.

Elliston, B. MacGill, I. Diesendorf, M. 2014. Comparing least cost scenarios for $100 \%$ renewable electricity with low emission fossil fuel scenarios in the Australian National Electricity Market. Renewable Energy 66, 196-204.

Environmental and Sustainable Development Directorate (ESDD), 2013. Solar Feed-in Tariff. <www.environment.act.gov.au/energy/fit>, 16 May 2013.

European Photovoltaic Industry Association (EPIA). 2012. Sustainability of Photovoltaic Systems - Job Creation. EPIA Fact Sheet, 24 September 2012.

Garnaut, R. 2011. The Garnaut Review 2011. Australia in the global response to climate change. Cambridge University Press; 2001.

Independent Pricing and Regulatory Tribunal (IPART). 2012. Solar feed-in tariffs: Setting a fair and reasonable value for electricity generated by small-scale solar PV units in NSW. Energy - Final Report March 2012.

Industry and Investment NSW, 2010. NSW Electricity Network and Prices Inquiry, Final Report. December 2010. 
Please reference the final published version, available at:

https://doi.org/10.1016/j.renene.2015.09.061

Intelligent Energy Systems, 2012. Analysis of Possible Modifications to the Queensland Solar Feed-in Tariff, Report for the Clean Energy Council. 22 June 2012.

Kent, A. Mercer, D. 2006. Australia's mandatory renewable energy target (MRET): an assessment. Energy Policy, 34(9), 1046-1062.

Macintosh, A. Wilkinson, D. 2011. Searching for public benefits in solar subsidies: A case study on the Australian government's residential photovoltaic rebate program. Energy Policy 39, 3199-3209.

Martin, N. Rice, J. 2012. Developing renewable energy supply in Queensland, Australia: A study of the barriers, targets, policies and actions. Renewable Energy 44, 119-127.

Menanteau, P. Finon, D. \& Lamy, M. 2003. Prices versus quantities : choosing policies for promoting the development of renewable energy $31,799-812$

Moosavian, S. Rahim, N. Selvaraj, J. Solangi, K. 2013. Energy policy to promote photovoltaic generation. Renewable and Sustainable Energy Reviews 25, 44-58.

Muhammad-Sukki, F. Abu-Bakar, S. Munir, A. Yasin, S. Ramirez-Iniguez, R. McMeekin, S. Stewart, B. Sarmah, N. Mallick, T. Rahim, R. Karim, M. Ahmad, S. Tahar, R. 2014. Feed-in tariff for solar photovoltaic: The rise of Japan. Renewable Energy 68, 636-643.

Nelson, T. Simshauser, P. Kelley, S. 2011. Australian Residential Solar Feed-in Tariffs: Industry Stimulus or Regressive form of Taxation? Economic Analysis \& Policy 41(2), 113-129.

New South Wales Trade and Investment. 2013. Solar Bonus Scheme. < http://www.resourcesandenergy.nsw.gov.au/energy-consumers/sustainableenergy/solar/small-scale/solar-bonus-schemes, 18 May, 2013.

Queensland Competition Authority (QCA). 2013. Final Report - Estimating a Fair and Reasonable Solar Feed in Tariff for Queensland. QCA, Brisbane, Australia.

Simpson, G. Clifton, J. 2014. Picking winners and policy uncertainty: Stakeholder perceptions of Australia's Renewable Energy Target. Renewable Energy 67, 128-135.

Solar Choice. 2014. Solar REC Zone Map. < http://www.solarchoice.net.au/blog/wpcontent/uploads/solar-REC-zone-map.png>, 12 May 2014.

Valentine, S. 2010. Braking wind in Australia: A critical evaluation of the renewable energy target. Energy Policy 38, 3668-3675.

Vivid Economics. 2013. Analysis of electricity consumption, electricity generation emissions intensity and economy-wide emissions, report prepared for the Climate Change Authority, October 2013.

World Wildlife Fund (WWF) and World Resources Institute (WRI). 2013. Meeting Renewable Energy Targets: Global lessons from the road to implementation. Report, 2013. 
Please reference the final published version, available at:

https://doi.org/10.1016/j.renene.2015.09.061

Zahedi, A. 2010. Australian renewable energy progress. Renewable and Sustainable Energy Reviews 14, 2208-2213.

Zahedi, A. 2010. A review of feed-in tariff in Australia, what it is now and what it should be. Renewable and Sustainable Energy Reviews 14, 3252-3255. 